\title{
Erythropoiesis stimulating agents and reno-protection: a meta-analysis
}

\author{
Steve Elliott ${ }^{*}$ (DD , Dianne Tomita ${ }^{1}$ and Zoltan Endre ${ }^{2}$
}

\begin{abstract}
Background: Erythropoiesis stimulating agents (ESAs) were proposed to enhance survival of renal tissues through direct effects via activation of EPO receptors on renal cells resulting in reduced cell apoptosis, or indirect effects via increased oxygen delivery due to increased numbers of $\mathrm{Hb}$ containing red blood cells. Thus through several mechanisms there may be benefit of ESA administration on kidney disease progression and kidney function in renal patients. However conflicting ESA reno-protection outcomes have been reported in both pre-clinical animal studies and human clinical trials. To better understand the potential beneficial effects of ESAs on renal-patients, meta-analyses of clinical trials is needed.

Methods: Literature searches and manual searches of references lists from published studies were performed. Controlled trials that included ESA treatment on renal patients with relevant renal endpoints were selected.

Results: Thirty two ESA controlled trials in 3 categories of intervention were identified. These included 7 trials with patients who had a high likelihood of AKl, 7 trials with kidney transplant patients and 18 anemia correction trials with chronic kidney disease (predialysis) patients. There was a trend toward improvement in renal outcomes in the ESA treated arm of AKI and transplant trials, but none reached statistical significance. In 12 of the anemia correction trials, meta-analyses showed no difference in renal outcomes with the anemia correction but both arms received some ESA treatment making it difficult to assess effects of ESA treatment alone. However, in 6 trials the low Hb arm received no ESAs and meta-analysis also showed no difference in renal outcomes, consistent with no benefit of ESA/ Hb increase.

Conclusions: Most ESA trials were small with modest event rates. While trends tended to favor the ESA treatment arm, these meta-analyses showed no reduction of incidence of AKl, no reduction in DGF or improvement in 1-year graft survival after renal transplantation and no significant delay in progression of CKD. These results do not support significant clinical reno-protection by ESAs.
\end{abstract}

Keywords: AKI (acute kidney injury), Anemia, Clinical trial, EPO, Erythropoietin, ESA, Meta-analysis, Progression of CKD, Reno-protection, Tissue protection, Transplant

\section{Background}

Erythropoietin (EPO) is a circulating hormone produced by the kidney, that stimulates erythropoiesis by binding and activating the EPO receptors (EPOR) on erythroid progenitor cells [1]. Subjects with chronic kidney disease (CKD) often develop anemia because of decreased production of EPO resulting in insufficient erythropoiesis. The cloning of the EPO gene allowed treatment of anemia in CKD patients by stimulating erythropoiesis with rHuEpo or other erythropoiesis stimulating agents (ESAs) [2].

\footnotetext{
* Correspondence: elliottsge@gmail.com

${ }^{1}$ Amgen Inc, One Amgen Center, Newbury Park, Thousand Oaks, CA 91320, USA

Full list of author information is available at the end of the article
}

Chronic anemia can result in organ damage affecting the cardiovascular system, kidneys, and the central nervous system [3-6] thus anemia correction might improve outcomes. In addition, EPOR was reported in nonhematopoietic tissues including renal cells [1], with some preclinical data suggesting that ESAs may be renoprotective due activation of EPOR resulting in antiapoptotic effects $[7,8]$. Some data suggest ESAs are reno-protective through an EpoR:CD131 complex and that EPO derivatives lacking erythropoietic activity are still reno-protective [9]. Other data conflicts with both hypotheses $[1,10]$. However, the possibility ESAs might mitigate the serious consequences of renal ischemia 
through direct (anti-apoptosis of renal cells) or indirect effects (increased oxygen delivery with increased $\mathrm{Hb}$ ) resulted in clinical trials to assess the potential benefit of ESA treatment in humans with renal diseases, and analysis of the results of those trials is warranted.

Clinical interventions to see if there is a relationship between ESAs and renal outcomes included short-term prophylactic ESA treatment where there was a high likelihood of acute kidney injury (AKI), e.g., patients undergoing coronary artery bypass grafting (CABG) surgery. In another modality, ESA treatment at the time of surgery might mitigate the ischemic damage and delayed graft function (DGF) that occurs during the perioperative period following kidney transplant. DGF increases the risk of acute rejection, impaired graft function, and reduces long term patient and graft survival. In a third modality, treatment of CKD patients to correct anemia associated with renal failure presumes that ESA treatment might delay or prevent renal disease progression through direct anti-apoptotic effects on renal cells or indirect effects of anemia correction, eg improved oxygen delivery.

Most of the trials examining the effect of ESAs on renal patients were small, outcomes were not robust or they varied across studies. Therefore, results from individual trials were inconclusive, but meta-analyses of results from those clinical trials may allow more definitive conclusions. We reasoned further that metaanalysis of multiple modalities would add additional value. The three modalities above were selected for meta-analysis because they examined direct and/or indirect effects of ESAs on renal disease progression or renal function. We report here that meta-analyses show no significant beneficial effects in any of the modalities, suggesting that ESAs have little reno-protective benefits, at least with the patient populations examined and clinical designs employed.

\section{Methods}

We wished to assess the effect of ESAs on kidneys by analyzing data from human clinical trials where ESAs might mitigate effects of ischemia or disease progression. This necessitated comprehensive searches and identification and analysis of controlled trials with renal patients where ESAs were used to protect kidneys from ischemia or to slow renal disease progression. All trials that had relevant renal endpoints were selected and analyzed, and data was extracted from those that might test the hypothesis.

\section{Search strategy}

Literature searches were performed using OVIDSP (Wolters Kluwer companies) to access MEDLINE and other databases including Current contents, Embase and BIOSYS previews, using search terms for ESAs (EPO, erythropoietin, rHuEpo, rEpo, epoetin, darbepoetin) in combination with anemia terms (anemia, $\mathrm{Hb}$, hemoglobin, hct, hematocrit), kidney or kidney injury (renal, kidney, transplant, CKD, chronic kidney disease, delayed graft function, DGF, acute kidney injury, and AKI), and terms describing possible beneficial outcome (protect, protection, reno-protection). Searches of the Clinicaltrials.gov and the Cochran database websites were performed using ESA terms combined with anemia, renal, kidney and transplant, to further identify potential papers of interest. A manual search of the reference lists in papers, review articles and other meta-analyses identified additional papers.

\section{Trial selection/inclusion criteria}

Papers considered for inclusion described human clinical data with ESA treatment and renal endpoints. Papers were rejected if they were not controlled trials, were case reports, described only preclinical data, or lacked the relevant renal endpoints. Papers with ESA treatment of renal patients on dialysis were omitted because renal disease progression was not applicable. The final list included controlled clinical trials that utilized ESAs in transplantation, AKI, and for anemia correction in predialysis CKD patients.

\section{Data extraction}

The data was recovered by SE and reviewed by ZE. Recovered data included the study characteristics, study location, length of study, ESA treatment, nature of the comparator arm, number of subjects in each arm, time intervals and definitions of renal endpoints. Results were grouped according to study type (patients presenting with or at risk of AKI, studies with kidney transplant patients, and CKD patients undergoing anemia correction). For trials involving AKI, data collected for meta-analysis was the number of patients with AKI and number of patients with renal recovery following AKI. Other endpoints recovered from those trials were any creatininebased or enzymatic markers that were measures of renal function or renal injury. With kidney transplant studies the measures recovered for meta-analysis were incidence of DGF within the first week post-surgery and graft loss/ survival over a 1 year period. Other data collected were any creatinine-based data, incidence of proteinuria, and enzymatic-based markers of renal injury. The metaanalysis endpoint in anemia correction trials was incidence of progression to renal replacement therapy (RRT; progression to dialysis or kidney transplant) at any time during the study. Other data recovered were, estimated glomerular filtration rate (eGFR), serum creatinine $(\mathrm{sCr})$, and their rate of change over time, and incidence of proteinuria. All the trial information and secondary 
measures are summarized in Tables 2, 3 and 4 . The data used in meta-analysis are shown in Figs. 3, 4, 5 and 6.

Data extracted to assess trial quality (bias) included randomization, concealment of allocation, masking of patients and clinicians, documentation of dropouts and withdrawals, and whether analysis was by intentionto-treat.

\section{Statistical analysis}

Data were summarized using Comprehensive MetaAnalysis Software (V2) (Biostat, Inc., Englewood, NJ, USA). A random-effects model was used because it assumes treatment effects are not identical in all studies. However, results of analyses using a fixed-effects model, which assumes that the treatment effect is the same in each study and that differences in results are due only to chance, are also provided when the $\mathrm{I}^{2}$ statistic was not equal to zero. Risk ratios (RR) and 95\% confidence intervals were calculated to compare results for patients treated with ESA with the control group. Heterogeneity or inconsistency across studies was assessed using Cochrane's Q ( $p$-value) and the $\mathrm{I}^{2}$ statistic. The $p$-value for the z-test comparing treatment groups was also determined.

\section{Results}

Description of searches and study selection criteria

The titles of papers from the searches were reviewed, and abstracts examined. Papers with potential relevance to ESAs, human clinical trials and tissue protection were recovered. This process resulted in 4056 papers. The selection and rejection process for these papers is shown in Fig. 1. Papers describing non-human studies, were reviews, were not clinical trials, lacked renal endpoints, were not in English, did not include a term for anemia, $\mathrm{Hb}$ or an ESA in the paper, or they did not otherwise fulfill the inclusion criteria were excluded. The resulting 309 papers described clinical trials with ESA-treated subjects that fell into 3 categories, at risk or presenting with AKI, ESA-treated kidney transplant patients and patients undergoing anemia correction with ESAs. Papers describing trials on dialysis patients, trials lacking a control group, trials that did not use ESAs, or were case studies, were omitted. Choukroun 2012 [11] was an anemia correction trial on renal transplant patients and not CKD patients so it was omitted. In 3 trials, ESAs were given prior to renal transplant [12-15] and omitted because there could be no direct effect of ESA on the ischemic transplanted kidney. Duplications were

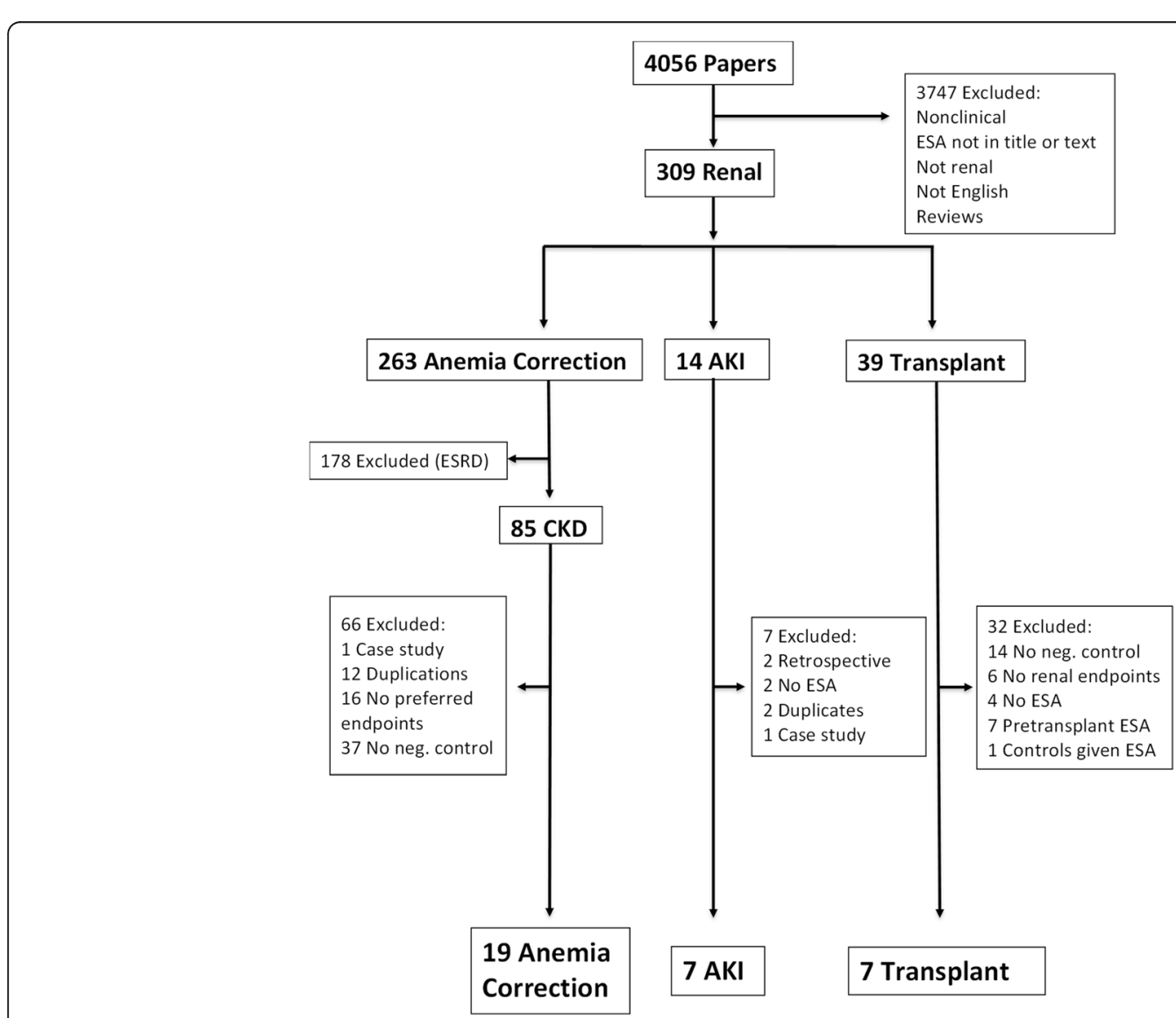

Fig. 1 Flow chart of study selection 
Table 1 Assessment of Risk of Bias of Randomized Controlled Trials

\begin{tabular}{|c|c|c|c|c|c|c|c|}
\hline Reference & $\begin{array}{l}\text { Trial } \\
\text { features }\end{array}$ & $\begin{array}{l}\text { Randomized } \\
\text { sequence }\end{array}$ & $\begin{array}{l}\text { Allocation } \\
\text { concealment }\end{array}$ & $\begin{array}{l}\text { Blinding of } \\
\text { outcome assessors }\end{array}$ & ITT analysis & $\begin{array}{l}\text { Reports on } \\
\text { Lost patients }\end{array}$ & $\begin{array}{l}\text { All patients treated } \\
\text { in assigned group }\end{array}$ \\
\hline $\begin{array}{l}\text { Dardashti } \\
2014 \text { [24] }\end{array}$ & $\mathrm{AKI}: \mathrm{DB}, \mathrm{SS}$ & $\begin{array}{l}\text { Low risk: patients } \\
\text { were randomly } \\
\text { allocated. }\end{array}$ & $\begin{array}{l}\text { Low risk: sequentially } \\
\text { numbered, sealed, \& } \\
\text { opaque envelopes. } \\
\text { Independent nurses } \\
\text { prepared the study drug } \\
\text { \& syringes were } \\
\text { delivered blinded }\end{array}$ & High risk & $\begin{array}{l}\text { High risk: } 5 \\
\text { patients that } \\
\text { received study } \\
\text { drug were } \\
\text { discontinued } \\
\text { and excluded } \\
\text { from analysis }\end{array}$ & $\begin{array}{l}\text { Low risk: lost } \\
\text { patients } \\
\text { reported }\end{array}$ & $\begin{array}{l}\text { Low risk: all patients } \\
\text { treated }\end{array}$ \\
\hline $\begin{array}{l}\text { deSeigneux } \\
2012 \text { [76] }\end{array}$ & AKI: DB, SS & $\begin{array}{l}\text { Low risk: a } \\
\text { randomization } \\
\text { code was } \\
\text { generated by } \\
\text { computer }\end{array}$ & $\begin{array}{l}\text { Low risk: envelopes with } \\
\text { allocation were prepared } \\
\text { by the quality of care } \\
\text { unit. A nurse opened the } \\
\text { envelopes and prepared } \\
\text { the syringes for injection. } \\
\text { Investigators and } \\
\text { patients were blinded to } \\
\text { the treatment }\end{array}$ & High risk & $\begin{array}{l}\text { Low risk: AKI } \\
\text { data on all } \\
\text { patients }\end{array}$ & $\begin{array}{l}\text { Low risk: lost } \\
\text { patients } \\
\text { reported }\end{array}$ & $\begin{array}{l}\text { Low risk: all patients } \\
\text { treated }\end{array}$ \\
\hline $\begin{array}{l}\text { Endre } 2010 \\
{[26]}\end{array}$ & $\begin{array}{l}\text { AKI: DB, MS } \\
\text { (2 centers) }\end{array}$ & $\begin{array}{l}\text { Low risk: } \\
\text { allocation by a } \\
\text { predefined } \\
\text { computer- } \\
\text { generated } \\
\text { randomization } \\
\text { sequence }\end{array}$ & $\begin{array}{l}\text { Low risk: concealment } \\
\text { was by a pharmacist; } \\
\text { pairs of identical } \\
\text { syringes. Patients, all } \\
\text { medical staff, \& } \\
\text { investigators were } \\
\text { blinded to treatment }\end{array}$ & $\begin{array}{l}\text { Low risk: Data Safety } \\
\text { Monitoring Board } \\
\text { with unmasking } \\
\text { followed recording of } \\
\text { the final AEs of the } \\
\text { patient last enrolled }\end{array}$ & Low risk & $\begin{array}{l}\text { Low risk: lost } \\
\text { patients } \\
\text { reported }\end{array}$ & $\begin{array}{l}\text { Low risk: but } 1 \\
\text { patient withdrew }\end{array}$ \\
\hline Kim 2013 [27] & AKI: DB, SS & $\begin{array}{l}\text { Low risk: } \\
\text { computer- } \\
\text { generated random } \\
\text { code }\end{array}$ & $\begin{array}{l}\text { Low risk: medications } \\
\text { were prepared by a } \\
\text { nurse who knew the } \\
\text { patient's group } \\
\text { assignment but was not } \\
\text { involved in the study }\end{array}$ & Unclear risk & $\begin{array}{l}\text { Low risk: No } \\
\text { dropouts }\end{array}$ & $\begin{array}{l}\text { Low risk: lost } \\
\text { patients } \\
\text { reported }\end{array}$ & $\begin{array}{l}\text { Low risk: all patients } \\
\text { treated }\end{array}$ \\
\hline Oh 2012 [16] & AKI: DB, SS & $\begin{array}{l}\text { Low risk: A } \\
\text { randomization } \\
\text { code list with a } \\
\text { block size of two } \\
\text { was generated. } \\
\text { Treatments were } \\
\text { allocated to } \\
\text { patients through } \\
\text { the Internet in } \\
\text { accordance with } \\
\text { the predefined } \\
\text { randomization list }\end{array}$ & $\begin{array}{l}\text { Low risk: a research } \\
\text { coordinator performed } \\
\text { randomization and } \\
\text { prepared the study } \\
\text { drugs }\end{array}$ & Unclear risk & Low risk & $\begin{array}{l}\text { Low risk: all } \\
\text { patients } \\
\text { completed } \\
\text { the trial }\end{array}$ & $\begin{array}{l}\text { Low risk: all patients } \\
\text { completed the trial }\end{array}$ \\
\hline $\begin{array}{l}\text { Tasanarong } \\
2013 \text { [28] }\end{array}$ & AKI: DB, SS & $\begin{array}{l}\text { Low risk: treatment } \\
\text { assignment by } \\
\text { blocked } \\
\text { randomization. } \\
\text { Sealed envelopes } \\
\text { containing the } \\
\text { allocation group } \\
\text { were opened by } \\
\text { nurses who did } \\
\text { not participate in } \\
\text { the study }\end{array}$ & $\begin{array}{l}\text { Low risk: treatments } \\
\text { were blindly given to } \\
\text { the research coordinator. } \\
\text { Patients and } \\
\text { investigators were } \\
\text { blinded to group } \\
\text { assignment. Pairs of } \\
\text { identical syringes } \\
\text { containing either } \\
\text { rHuEPO or saline were } \\
\text { prepared }\end{array}$ & High risk & $\begin{array}{l}\text { Low risk: No } \\
\text { dropouts }\end{array}$ & $\begin{array}{l}\text { Low risk: no } \\
\text { dropouts }\end{array}$ & Low risk: no dropouts \\
\hline Yoo 2011 [29] & $\begin{array}{l}\text { AKI: } \\
\text { OL(single } \\
\text { blinded), SS }\end{array}$ & $\begin{array}{l}\text { Low risk: patients } \\
\text { were allocated by } \\
\text { computer- } \\
\text { generated random } \\
\text { numbers }\end{array}$ & $\begin{array}{l}\text { Unclear risk: medications } \\
\text { were prepared and } \\
\text { administered by a ward } \\
\text { physician recognizing the } \\
\text { patient's group but not } \\
\text { involved in the current } \\
\text { study, the surgeon and } \\
\text { anesthesiologist involved } \\
\text { were blinded }\end{array}$ & $\begin{array}{l}\text { Low risk: the surgeon } \\
\text { and anesthesiologist } \\
\text { involved in the study } \\
\text { and patient } \\
\text { management were } \\
\text { blinded to the } \\
\text { patients' groups until } \\
\text { the end of the study }\end{array}$ & $\begin{array}{l}\text { Low risk: } \\
\text { complete data } \\
\text { sets from the } \\
74 \text { patients } \\
\text { were analyzed } \\
\text { without any } \\
\text { missing data }\end{array}$ & $\begin{array}{l}\text { Low risk: no } \\
\text { dropouts }\end{array}$ & $\begin{array}{l}\text { Low risk: complete } \\
\text { data sets from the } 74 \\
\text { patients were } \\
\text { analyzed without any } \\
\text { missing data }\end{array}$ \\
\hline $\begin{array}{l}\text { Aydin } 2012 \\
{[31]}\end{array}$ & $\begin{array}{l}\text { Transplant: } \\
\text { DB, SS }\end{array}$ & $\begin{array}{l}\text { Low risk: Patients } \\
\text { were randomized } \\
\text { by an independent } \\
\text { hospital pharmacist. } \\
\text { The randomization } \\
\text { allocation } \\
\text { sequence was } \\
\text { generated by a } \\
\text { random-number } \\
\text { table }\end{array}$ & $\begin{array}{l}\text { Low risk: patients, } \\
\text { physicians, data } \\
\text { managers and } \\
\text { investigators were kept } \\
\text { blinded throughout the } \\
\text { study }\end{array}$ & $\begin{array}{l}\text { Low risk: data } \\
\text { managers and } \\
\text { investigators were } \\
\text { kept blinded } \\
\text { throughout the study }\end{array}$ & $\begin{array}{l}\text { Low risk: No } \\
\text { dropouts }\end{array}$ & $\begin{array}{l}\text { Low risk: No } \\
\text { dropouts }\end{array}$ & $\begin{array}{l}\text { Low risk: No } \\
\text { dropouts }\end{array}$ \\
\hline
\end{tabular}


Table 1 Assessment of Risk of Bias of Randomized Controlled Trials (Continued)

\begin{tabular}{|c|c|c|c|c|c|c|c|}
\hline $\begin{array}{l}\text { Coupes } 2015 \\
{[30]}\end{array}$ & $\begin{array}{l}\text { Transplant: } \\
\text { DB, SS }\end{array}$ & $\begin{array}{l}\text { Low risk: patients } \\
\text { were randomly } \\
\text { assigned by the } \\
\text { trial pharmacy by } \\
\text { computer }\end{array}$ & $\begin{array}{l}\text { Low risk: all study } \\
\text { participants and the } \\
\text { study team were blinded } \\
\text { to the trial drug }\end{array}$ & Unclear risk & $\begin{array}{l}\text { Low risk: } 1 \\
\text { patient } \\
\text { withdrew but } \\
\text { was included } \\
\text { in the analysis }\end{array}$ & $\begin{array}{l}\text { Low risk: lost } \\
\text { patients } \\
\text { reported }\end{array}$ & Low risk \\
\hline $\begin{array}{l}\text { Hafer } 2012 \\
\text { [32] }\end{array}$ & $\begin{array}{l}\text { Transplant: } \\
\text { DB, SS }\end{array}$ & $\begin{array}{l}\text { Unclear risk: } \\
\text { randomization } \\
\text { methodology not } \\
\text { disclosed }\end{array}$ & $\begin{array}{l}\text { Low risk: vials containing } \\
\text { ESA and placebo had } \\
\text { identical appearance }\end{array}$ & Unclear risk & $\begin{array}{l}\text { Low risk for } \\
\text { DGF. High risk } \\
\text { for graft loss } \\
\text { ( } 3 \text { patients } \\
\text { died } 1 \text { in ESA } \\
\text { group and } 2 \\
\text { in placebo } \\
\text { group) }\end{array}$ & $\begin{array}{l}\text { Low risk: lost } \\
\text { patients } \\
\text { reported }\end{array}$ & $\begin{array}{l}\text { High risk: } 2 \text { untreated } \\
\text { patients (not } \\
\text { included in analysis) } \\
\text { and } 3 \text { patients died }\end{array}$ \\
\hline $\begin{array}{l}\text { Martinez } 2010 \\
\text { [33] }\end{array}$ & $\begin{array}{l}\text { Transplant: } \\
\text { OL, MC }\end{array}$ & $\begin{array}{l}\text { Unclear risk: } \\
\text { randomization } \\
\text { method not } \\
\text { disclosed }\end{array}$ & $\begin{array}{l}\text { High risk: comparator } \\
\text { arm was untreated }\end{array}$ & $\begin{array}{l}\text { Low risk: Blinded } \\
\text { evaluation of end- } \\
\text { points }\end{array}$ & $\begin{array}{l}\text { Unclear risk: } 1 \\
\text { died in ESA } \\
\text { group }\end{array}$ & $\begin{array}{l}\text { Low risk: lost } \\
\text { patients } \\
\text { reported }\end{array}$ & Low risk \\
\hline $\begin{array}{l}\text { Sureshkumar } \\
2012[34]\end{array}$ & $\begin{array}{l}\text { Transplant: } \\
\text { DB, SS }\end{array}$ & $\begin{array}{l}\text { Low risk: the } \\
\text { hospital pharmacy } \\
\text { created a schedule } \\
\text { using random } \\
\text { assignments to a } \\
\text { series of patient } \\
\text { study numbers }\end{array}$ & $\begin{array}{l}\text { Low risk: ESA and } \\
\text { placebo were both } 1 \mathrm{ml} \\
\text { syringes. The } \\
\text { medications were } \\
\text { administered in a } \\
\text { double-blinded manner }\end{array}$ & Unclear risk & Low risk & $\begin{array}{l}\text { Low risk: no } \\
\text { dropouts }\end{array}$ & Low risk \\
\hline $\begin{array}{l}\text { Van Biesen } \\
2005 \text { [35] }\end{array}$ & $\begin{array}{l}\text { Transplant: } \\
\text { OL, SS }\end{array}$ & $\begin{array}{l}\text { Unclear risk: } \\
\text { randomization } \\
\text { method not } \\
\text { disclosed }\end{array}$ & High risk: open label & High risk & Unclear risk & High risk & Unclear risk \\
\hline $\begin{array}{l}\text { Van Loo } 1996 \\
\text { [36] }\end{array}$ & $\begin{array}{l}\text { Transplant: } \\
\text { OL, SS }\end{array}$ & $\begin{array}{l}\text { Unclear risk: } \\
\text { randomization } \\
\text { method not } \\
\text { disclosed }\end{array}$ & High risk: open label & High risk & $\begin{array}{l}\text { Low risk: no } \\
\text { deaths or } \\
\text { withdrawals }\end{array}$ & $\begin{array}{l}\text { Low risk: no } \\
\text { deaths or } \\
\text { withdrawal }\end{array}$ & $\begin{array}{l}\text { Low risk: no deaths } \\
\text { or withdrawals }\end{array}$ \\
\hline $\begin{array}{l}\text { Abraham } \\
1990[38]\end{array}$ & $\begin{array}{l}\text { Anemia } \\
\text { correction: } \\
\text { DB then } \\
\text { OL, Anemia } \\
\text { correction: } \\
\text { SS }\end{array}$ & $\begin{array}{l}\text { Unclear risk: } \\
\text { randomization } \\
\text { method not } \\
\text { disclosed }\end{array}$ & Unclear risk: unspecified & High risk & $\begin{array}{l}\text { Low risk: no } \\
\text { dropouts }\end{array}$ & $\begin{array}{l}\text { Low risk: no } \\
\text { dropouts }\end{array}$ & Low risk \\
\hline $\begin{array}{l}\text { Clyne } 1992 \\
\text { [39] }\end{array}$ & $\begin{array}{l}\text { Anemia } \\
\text { correction: } \\
\text { OL, } 2 \\
\text { center }\end{array}$ & Unclear risk & High risk & High risk & $\begin{array}{l}\text { Low risk: for } \\
\text { RRT }\end{array}$ & $\begin{array}{l}\text { Low risk: lost } \\
\text { patients } \\
\text { reported }\end{array}$ & Low risk \\
\hline $\begin{array}{l}\text { Kleinman } \\
1989[40]\end{array}$ & $\begin{array}{l}\text { Anemia } \\
\text { correction: } \\
\text { DB, MC }\end{array}$ & $\begin{array}{l}\text { Unclear risk: } \\
\text { randomization } \\
\text { method not } \\
\text { specified }\end{array}$ & Unclear risk: unspecified & High risk & $\begin{array}{l}\text { Unclear risk: } \\
\text { no dropouts } \\
\text { reported }\end{array}$ & $\begin{array}{l}\text { Unclear risk: } \\
\text { no dropouts } \\
\text { reported }\end{array}$ & Low risk \\
\hline $\begin{array}{l}\text { Kuriyama } \\
1997[41]\end{array}$ & $\begin{array}{l}\text { Anemia } \\
\text { correction: } \\
\text { OL, SS }\end{array}$ & Unclear risk & High risk & High risk & Low risk & $\begin{array}{l}\text { Low risk: lost } \\
\text { patients } \\
\text { reported }\end{array}$ & Low risk \\
\hline Lim 1989 [42] & $\begin{array}{l}\text { Anemia } \\
\text { correction: } \\
\text { DB, SS }\end{array}$ & $\begin{array}{l}\text { Low risk: } \\
\text { randomization by } \\
\text { third party }\end{array}$ & Unclear risk & Unclear risk & High risk & $\begin{array}{l}\text { Low risk: lost } \\
\text { patients } \\
\text { reported }\end{array}$ & Low risk \\
\hline $\operatorname{Lim} 1990$ [43] & $\begin{array}{l}\text { Anemia } \\
\text { correction: } \\
\text { OL, SS }\end{array}$ & Unclear risk & High risk & High risk & $\begin{array}{l}\text { Low risk: no } \\
\text { dropouts }\end{array}$ & $\begin{array}{l}\text { Low risk: no } \\
\text { dropouts }\end{array}$ & Low risk \\
\hline $\begin{array}{l}\text { Revicki } 1995 \\
{[18]}\end{array}$ & $\begin{array}{l}\text { Anemia } \\
\text { correction: } \\
\text { OL, MC }\end{array}$ & High risk & High risk & High risk & $\begin{array}{l}\text { Low risk: for } \\
\text { RRT endpoint }\end{array}$ & $\begin{array}{l}\text { Low risk: lost } \\
\text { patients } \\
\text { reported }\end{array}$ & Unclear risk \\
\hline $\begin{array}{l}\text { Cianciaruso } \\
2008[45]\end{array}$ & $\begin{array}{l}\text { Anemia } \\
\text { correction: } \\
\text { OL, MC }\end{array}$ & $\begin{array}{l}\text { Low risk: } \\
\text { randomization by } \\
\text { computer at a } \\
\text { separate site }\end{array}$ & $\begin{array}{l}\text { Low risk: allocation was } \\
\text { concealed from } \\
\text { investigators, sequences } \\
\text { were sequentially } \\
\text { numbered in opaque } \\
\text { envelopes opened in } \\
\text { sequence }\end{array}$ & High risk & Low risk & $\begin{array}{l}\text { Low risk: lost } \\
\text { patient } \\
\text { reports }\end{array}$ & $\begin{array}{l}\text { High risk: } 1 \text { patient in } \\
\text { the treatment group } \\
\text { did not receive ESA, } \\
\text { study terminated } \\
\text { early }\end{array}$ \\
\hline $\begin{array}{l}\text { Gouva } 2004 \\
{[47]}\end{array}$ & $\begin{array}{l}\text { Anemia } \\
\text { correction: } \\
\text { OL, MC }\end{array}$ & $\begin{array}{l}\text { Low risk: } \\
\text { computer } \\
\text { generated } \\
\text { sequence }\end{array}$ & Unclear risk & High risk & Low risk & $\begin{array}{l}\text { Low risk: lost } \\
\text { patients } \\
\text { reported }\end{array}$ & $\begin{array}{l}\text { High risk: study } \\
\text { prematurely } \\
\text { terminated }\end{array}$ \\
\hline
\end{tabular}


Table 1 Assessment of Risk of Bias of Randomized Controlled Trials (Continued)

\begin{tabular}{|c|c|c|c|c|c|c|c|}
\hline $\begin{array}{l}\text { Levin } 2005 \\
{[48]}\end{array}$ & $\begin{array}{l}\text { Anemia } \\
\text { correction: } \\
\text { OL, MC }\end{array}$ & $\begin{array}{l}\text { Low risk: } \\
\text { computer } \\
\text { generated } \\
\text { sequence }\end{array}$ & $\begin{array}{l}\text { Low risk: allocation was } \\
\text { in sealed sequentially } \\
\text { numbered opaque } \\
\text { envelopes. Designated } \\
\text { personnel opened the } \\
\text { next number in sequence }\end{array}$ & High risk & Low risk & $\begin{array}{l}\text { Low risk: lost } \\
\text { patient } \\
\text { reports }\end{array}$ & $\begin{array}{l}\text { High risk: only } 77 / 85 \\
\text { in the high Hb group } \\
\text { received ESA }\end{array}$ \\
\hline $\begin{array}{l}\text { MacDougall } \\
2007 \text { [49] }\end{array}$ & $\begin{array}{l}\text { Anemia } \\
\text { correction: } \\
\text { OL, MC }\end{array}$ & $\begin{array}{l}\text { Low risk: } \\
\text { randomized using } \\
\text { central } \\
\text { randomization } \\
\text { procedures } \\
\text { (ClinPhone) }\end{array}$ & Unclear risk & High risk & Low risk & $\begin{array}{l}\text { Low risk: lost } \\
\text { patients } \\
\text { reported }\end{array}$ & $\begin{array}{l}\text { High risk: patients in } \\
\text { the high Hb group } \\
\text { received ESA on day } \\
1 \text { but study was } \\
\text { prematurely } \\
\text { terminated }\end{array}$ \\
\hline $\begin{array}{l}\text { Pfeffer } 2009 \\
{[50]}\end{array}$ & $\begin{array}{l}\text { Anemia } \\
\text { correction: } \\
\text { DB, MC }\end{array}$ & $\begin{array}{l}\text { Low risk: DB, and } \\
\text { patients were } \\
\text { randomly assigned } \\
\text { with the use of a } \\
\text { computer- } \\
\text { generated, } \\
\text { permuted-block } \\
\text { design }\end{array}$ & Unclear risk & High risk & $\begin{array}{l}\text { High risk: } 9 \\
\text { patients were } \\
\text { excluded prior } \\
\text { to unblinding }\end{array}$ & $\begin{array}{l}\text { Low risk: lost } \\
\text { patient } \\
\text { reports }\end{array}$ & $\begin{array}{l}\text { High risk: } 93.9 \% \text { of } \\
\text { the patients in the } \\
\text { darbepoetin alfa } \\
\text { group were receiving } \\
\text { the assigned } \\
\text { treatment at } \\
6 \text { months" }\end{array}$ \\
\hline Ritz 2007 [51] & $\begin{array}{l}\text { Anemia } \\
\text { correction: } \\
\text { OL, MC }\end{array}$ & $\begin{array}{l}\text { Low risk: } \\
\text { randomization } \\
\text { was performed } \\
\text { centrally into } \\
\text { treatment groups } \\
\text { by using a block- } \\
\text { size randomization } \\
\text { procedure stratified } \\
\text { by country }\end{array}$ & Unclear risk & High risk & Low risk & $\begin{array}{l}\text { Low risk: lost } \\
\text { patient } \\
\text { reports }\end{array}$ & $\begin{array}{l}\text { Unclear risk: patients } \\
\text { in group } 1 \text { were } \\
\text { started immediately } \\
\text { ESA but } 3 \text { patients } \\
\text { withdrew }\end{array}$ \\
\hline $\begin{array}{l}\text { Roger } 2004 \\
{[52]}\end{array}$ & $\begin{array}{l}\text { Anemia } \\
\text { correction: } \\
\text { OL, MC }\end{array}$ & $\begin{array}{l}\text { Low risk: patients } \\
\text { were randomized } \\
\text { according to } \\
\text { computer- } \\
\text { generated } \\
\text { stratification tables }\end{array}$ & $\begin{array}{l}\text { Low risk: order } \\
\text { concealment was } \\
\text { maintained until the } \\
\text { intervention was } \\
\text { assigned }\end{array}$ & High risk & Low risk & $\begin{array}{l}\text { Low risk: lost } \\
\text { patient } \\
\text { reports }\end{array}$ & Low risk \\
\hline $\begin{array}{l}\text { Rossert } 2006 \\
\text { [53] }\end{array}$ & $\begin{array}{l}\text { Anemia } \\
\text { correction: } \\
\text { OL, MC }\end{array}$ & $\begin{array}{l}\text { Low risk: patients } \\
\text { were randomized } \\
\text { according to } \\
\text { computer- } \\
\text { generated } \\
\text { stratification } \\
\text { schedule }\end{array}$ & Unclear risk & High risk & Low risk & $\begin{array}{l}\text { Low risk: lost } \\
\text { patient } \\
\text { reports }\end{array}$ & $\begin{array}{l}\text { High risk: study was } \\
\text { terminated } \\
\text { prematurely. Many } \\
\text { subjects did not } \\
\text { enter maintenance or } \\
\text { withdrew }\end{array}$ \\
\hline $\begin{array}{l}\text { Villar } 2011 \\
\text { [55] }\end{array}$ & $\begin{array}{l}\text { Anemia } \\
\text { correction: } \\
\text { OL, MC }\end{array}$ & $\begin{array}{l}\text { Low risk: block- } \\
\text { size randomization } \\
\text { was used }\end{array}$ & Unclear risk & High risk & Low risk & $\begin{array}{l}\text { Low risk: lost } \\
\text { patients } \\
\text { reported }\end{array}$ & $\begin{array}{l}\text { Unclear risk: most } \\
\text { patients likely } \\
\text { received ESA but } 6 \\
\text { patients died or } \\
\text { withdrew }\end{array}$ \\
\hline $\begin{array}{l}\text { Akizawa } 2011 \\
\text { [44] }\end{array}$ & $\begin{array}{l}\text { Anemia } \\
\text { correction: } \\
\text { OL, MC }\end{array}$ & $\begin{array}{l}\text { Low risk: patients } \\
\text { were assigned by } \\
\text { a computer } \\
\text { according to a } \\
\text { minimization } \\
\text { method }\end{array}$ & Unclear risk & High risk & Low risk & $\begin{array}{l}\text { Low risk: lost } \\
\text { patients } \\
\text { reported }\end{array}$ & $\begin{array}{l}\text { High risk: after } 1 \\
\text { administration, } 43 \\
\text { withdrew. }\end{array}$ \\
\hline $\begin{array}{l}\text { Drueke } 2006 \\
\text { [46] }\end{array}$ & $\begin{array}{l}\text { Anemia } \\
\text { correction: } \\
\text { OL, MC }\end{array}$ & $\begin{array}{l}\text { Low risk: } \\
\text { randomization } \\
\text { was performed } \\
\text { centrally with the } \\
\text { use of a dynamic } \\
\text { randomization } \\
\text { method }\end{array}$ & Unclear risk & High risk & Low risk & $\begin{array}{l}\text { Low risk: lost } \\
\text { patients } \\
\text { reported }\end{array}$ & $\begin{array}{l}\text { High risk: } 75 \text { in the } \\
\text { high } \mathrm{Hb} \text { group } \\
\text { withdrew }\end{array}$ \\
\hline $\begin{array}{l}\text { Singh } 2006 \\
{[54]}\end{array}$ & $\begin{array}{l}\text { Anemia } \\
\text { correction: } \\
\mathrm{OL}, \mathrm{MC}\end{array}$ & $\begin{array}{l}\text { Low risk: patients } \\
\text { were assigned } \\
\text { by computer- } \\
\text { generated } \\
\text { per-muted-block } \\
\text { randomization }\end{array}$ & Unclear risk & High risk & Low risk & $\begin{array}{l}\text { Low risk: lost } \\
\text { patients } \\
\text { reported }\end{array}$ & $\begin{array}{l}\text { High risk: study was } \\
\text { terminated early at } \\
\text { the second interim } \\
\text { analysis because } \\
\text { power to demonstrate } \\
\text { benefit was less than } \\
5 \% \text {, and there was a } \\
\text { high withdrawal rate }\end{array}$ \\
\hline
\end{tabular}

*RCT-randomized controlled trial, DB Double blind, OL Open label, MC Multicenter, SC Single center 
identified; Oh 2012 [16] was a reanalysis of Song 2009 [17] and Revicki 1995 [18] was a follow-up of Roth 1994 [19]. The Park (2005) [20] and Olweny (2012) [21] trials were excluded from meta-analysis because they were retrospective trials without AKI endpoints. 33 papers published between 1989 and 2015 remained, and their characteristics and extracted data are summarized in Tables 2, 3 and 4. Measures of renal function (sCr, eGFR, and enzymatic) varied, (methods and times), or were not reported in many papers. Therefore, we chose not to perform meta-analyses using those markers but instead summarize available data in the tables. Meta-analyses (Forrest plots) using the selected hard endpoints, are shown in Figs. 3, 4, 5 and 6.

\section{Risk of bias assessment}

Trial quality (potential bias) was evaluated utilizing Jadad [22] and Cochrane recommendations. With the exception of Kamar 2010 [23] (which was a observational trial) all the trials used in meta-analysis were RCTs. Risk of bias assessment is shown in Table 1 and Fig. 2. Most trials provided an ITT analysis with reporting of lost patients. The trials also had adequate methods to randomly distribute subjects into intervention vs control groups. Blinding of subject distribution and blinding of outcome to assessors was inadequate in most trials, particularly the anemia correction trials. However, the hard renal endpoints used in these meta-analyses are strengths. Most AKI and transplant trials were doubleblinded with few dropouts, while the anemia correction trials were mostly open-label with variable numbers of dropouts. Overall, the trials had a risk of bias that was considered acceptable and thus results from metaanalysis would be informative.

\section{Outcomes and meta-analysis \\ AKI trials}

Nine trials were identified [16, 20, 21, 24-29] that assessed whether ESAs might reduce the risk of AKI (Table 2).
In 8 trials the subjects underwent cardiac surgery (coronary artery grafting, or valvular heart surgery involving cardiopulmonary bypass) and in 1 trial the subjects underwent partial nephrectomy. The combined number of subjects was 1020; 490 in the ESA groups and 530 in the control groups. The trial sizes ranged from 71 to 187 subjects. The number of ESA administrations were small (1 or 2 ) so there were little/no changes in $\mathrm{Hb}$ (Table 2 ).

The endpoint tested in the meta-analysis was the number of patients that developed AKI within 2-7 days ( $>50 \%$ increase serum creatinine, or $>0.3 \mathrm{mg} / \mathrm{dl}$ increase, AKIN definition). Four of the trials were performed by overlapping members of the same study groups [16, 17, 27, 29]. Song (2009) and Oh (2012) analyzed the same 71 patients and patient data, but used different definitions of AKI. They increased the duration of observation to 72 instead of $48 \mathrm{~h}$, and therefore had different numbers of patients that progressed to AKI. We used the determinations from Oh (2012) because it is more recent and the definition used is more complete (AKIN).

Overall 107 of 367 (29\%) of the subjects developed AKI in the ESA groups, with 133 of 357 (37\%) in the control groups (Fig. 3). The RR slightly favored the ESA arm, but it did not reach statistical significance using either the random effects $(0.79[0.55,1.14])$, or fixed effects models $(0.85[0.69,1.05])$. Heterogeneity was high $\left(\mathrm{I}^{2}=60 \%\right), 3$ trials showed benefit in the ESA arm, while the other 4 were neutral, or favored the control arm. This heterogeneity is further apparent when other renal endpoints were examined (Table 2). In 1 trial [20] there was no difference in renal recovery, in 4 trials there was no difference in creatinine-based markers. However, in a 5th mixed results were reported. In a 6th creatinine markers favored slightly $(p=0.054)$ the ESA group and in the $7^{\text {th }}$, creatinine-based markers favored the ESA group. In 3 trials there was no difference in eGFR between groups, while in another trial, eGFR was improved in the ESA arm. Overall the secondary outcome analyses

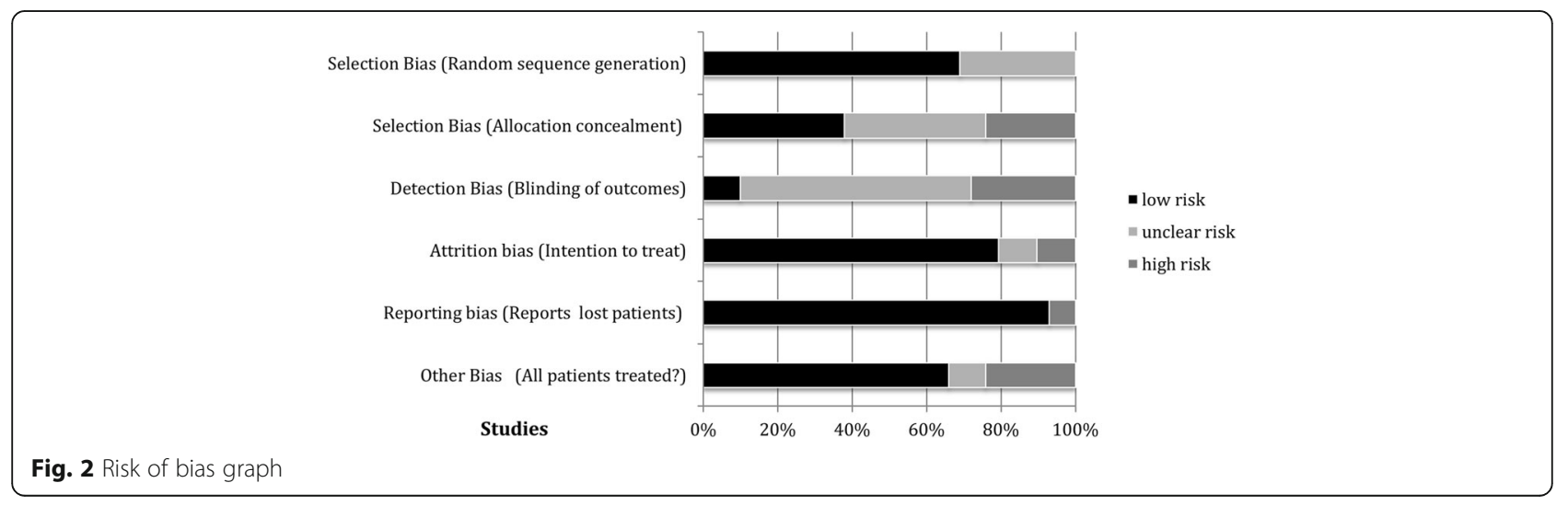


Table 2 AKI studies

\begin{tabular}{|c|c|c|c|c|c|c|c|}
\hline Reference & Study Location & $\begin{array}{l}\text { Patient } \\
\text { Population }\end{array}$ & ESA & Control & $\begin{array}{l}\text { Subjects } \\
\text { (Total and \# } \\
\text { in groups) }\end{array}$ & $\begin{array}{l}\text { Renal Injury } \\
\text { (AKI) Definition }\end{array}$ & Other Outcomes \\
\hline $\begin{array}{l}\text { Dardashti } \\
2014[24]\end{array}$ & $\begin{array}{l}\text { Sweden (Skåne } \\
\text { University } \\
\text { Hospital, Lund) }\end{array}$ & $\begin{array}{l}\text { Patients scheduled } \\
\text { for CABG with } \\
\text { preexisting renal } \\
\text { impairment }\end{array}$ & $\begin{array}{l}\text { Epoetin zeta } \\
(400 \mathrm{IU} / \mathrm{kg} ; \\
\left.\text { Retacrit }{ }^{\oplus}\right) \\
\text { administered } \\
\text { preoperative }\end{array}$ & $\begin{array}{l}\text { Equivalent } \\
\text { volume of } \\
\text { saline }\end{array}$ & $\begin{array}{l}N=70: \\
\text { ESA(35), } \\
\text { control(35) }\end{array}$ & $\begin{array}{l}\text { RIFLE on d3 based } \\
\text { on eGFR using the } \\
\text { Modification of Diet in } \\
\text { Renal Disease formula }\end{array}$ & $\begin{array}{l}\text { No difference in } \mathrm{Hb} \text {, } \\
\text { transfusions, relative } \\
\text { cystatin } \mathrm{C}, \mathrm{NGAL} \text {, } \\
\text { creatinine, urea, or eGFR) }\end{array}$ \\
\hline $\begin{array}{l}\text { deSeigneux } \\
2012 \text { [76] }\end{array}$ & $\begin{array}{l}\text { Switzerland } \\
\text { (University } \\
\text { Hospital, } \\
\text { Geneva) }\end{array}$ & $\begin{array}{l}\text { Patients admitted } \\
\text { to the ICU for } \\
\text { cardiac surgery }\end{array}$ & $\begin{array}{l}\text { ESA Group } 1 \\
\text { (20,000 IU; epoetin } \\
\text { a), group } 2 \text { ( } 40,000 \\
\text { Ul epoetin a) \& } \\
\text { group } 3 \text { (control) } 1 \\
\text { to } 4 \text { h post-surgery }\end{array}$ & $\begin{array}{l}\text { Isotonic } \\
\text { sodium } \\
\text { chloride }\end{array}$ & $\begin{array}{l}N=80: \\
\text { ESA group } \\
1(20), \text { ESA } \\
\text { group 2(20), } \\
\text { control(40) }\end{array}$ & $\begin{array}{l}\text { AKIN from ICU } \\
\text { admission to the } \\
\text { following wk }\end{array}$ & $\begin{array}{l}\text { No difference in } \mathrm{Hb} \text {, } \\
\text { creatinine, cystatin c, or } \\
\text { urinary NGAL levels }\end{array}$ \\
\hline $\begin{array}{l}\text { Endre } 2010 \\
{[26]}\end{array}$ & $\begin{array}{l}\text { New Zealand } \\
\text { (Christchurch } \\
\text { or Dunedin } \\
\text { Hospital) }\end{array}$ & $\begin{array}{l}\text { Patients admitted } \\
\text { to the ICU or high- } \\
\text { risk patients sched- } \\
\text { uled for cardio- } \\
\text { thoracic surgery } \\
\text { with CPB }\end{array}$ & $\begin{array}{l}\text { ESA (500 U/kg (iv) } \\
\text { to a maximum of } \\
50,000 \mathrm{U}) \text {, within } \\
6 \mathrm{~h} \text { of increased } \\
\text { GGT AP and a } \\
\text { second dose } 2 \mathrm{~h} \\
\text { later }\end{array}$ & $\begin{array}{l}\text { Equivalent } \\
\text { volume of } \\
\text { normal } \\
\text { saline }\end{array}$ & $\begin{array}{l}N=163: \\
\operatorname{ESA}(84) \\
\text { control(78) }\end{array}$ & $\begin{array}{l}\text { AKIN classification in } \\
7 \text { days }\end{array}$ & $\begin{array}{l}\text { No difference in any } \\
\text { creatinine-based } \\
\text { variables }\end{array}$ \\
\hline $\begin{array}{l}\text { Kim } 2013 \\
{[27]}\end{array}$ & $\begin{array}{l}\text { Korea (Yonsei } \\
\text { University } \\
\text { Health System, } \\
\text { Seoul) }\end{array}$ & $\begin{array}{l}\text { Patients with } \\
\text { preoperative risk } \\
\text { factors for AKI who } \\
\text { were scheduled for } \\
\text { complex valvular } \\
\text { heart operations }\end{array}$ & $\begin{array}{l}\text { Epoetin a (300 } \\
\text { IU/kg (iv); Epocain) } \\
\text { after anesthetic } \\
\text { induction }\end{array}$ & $\begin{array}{l}\text { Equivalent } \\
\text { volume of } \\
\text { normal } \\
\text { saline. }\end{array}$ & $\begin{array}{l}N=98: \\
\text { ESA(49), } \\
\text { control(49) }\end{array}$ & $\begin{array}{l}\text { An increase in serum } \\
\text { creatinine }>0.3 \mathrm{mg} / \mathrm{dl} \\
\text { or }>50 \% \text { from } \\
\text { baseline: }\end{array}$ & $\begin{array}{l}\text { No differences in } \mathrm{Hb} \text {, } \\
\text { sCr, eGFR, creatinine } \\
\text { clearance, cystatin } \mathrm{C} \text { or } \\
\text { serum NGAL }\end{array}$ \\
\hline $\begin{array}{l}\text { Olweny } \\
2012[21]\end{array}$ & $\begin{array}{l}\text { USA (UT } \\
\text { Southwestern, } \\
\text { Houston, } \\
\text { Texas) }\end{array}$ & $\begin{array}{l}\text { Patients who } \\
\text { underwent } \\
\text { laparoscopic partial } \\
\text { nephrectomy }\end{array}$ & $\begin{array}{l}\text { Epoetin a (500 } \\
\text { IU/kg (iv) Procrit) } \\
30 \text { min prior to LPN }\end{array}$ & No ESA & $\begin{array}{l}N=106: \\
\text { ESA(52), } \\
\text { control(54). }\end{array}$ & NA & No difference in eGFR \\
\hline $\begin{array}{l}\text { Oh } 2012 \\
{[16]}\end{array}$ & $\begin{array}{l}\text { Korea, National } \\
\text { University } \\
\text { Bundang } \\
\text { Hospital, Seoul }\end{array}$ & $\begin{array}{l}\text { Patients scheduled } \\
\text { for elective CABG }\end{array}$ & $\begin{array}{l}\text { Epoetin } \beta \text { ( } 300 \\
\text { U/kg Recormon) } \\
\text { before CABG }\end{array}$ & Saline & $\begin{array}{l}N=71: \\
\operatorname{ESA}(36,) \\
\text { control(35). }\end{array}$ & $\begin{array}{l}\mathrm{SCr} \geq 0.3 \mathrm{mg} / \mathrm{dL} \text { from } \\
\text { baseline, } \geq 50 \% \\
\text { increase in the } \mathrm{sCr} \\
\text { concentration in the } \\
\text { first } 72 \mathrm{~h} \text { after CABG, } \\
\text { or }<0.5 \mathrm{~mL} / \mathrm{kg} \text { per } \\
\text { hour of oliguria for } \\
\text { more than six hr }\end{array}$ & $\begin{array}{l}\text { sCr was not different } \\
\text { from baseline in the ESA } \\
\text { group, but was higher in } \\
\text { the placebo group. }\end{array}$ \\
\hline $\begin{array}{l}\text { Park } 2005 \\
{[20]}\end{array}$ & $\begin{array}{l}\text { USA (surgical } \\
\text { ICU), } \\
\text { cardiothoracic } \\
\text { ICU, or medical } \\
\text { ICU at Barnes- } \\
\text { Jewish Hos- } \\
\text { pital, St Louis, } \\
\text { Missouri) }\end{array}$ & $\begin{array}{l}\text { Patients scheduled } \\
\text { for elective CABG }\end{array}$ & $\begin{array}{l}\text { ESA (112 U/kg/ } \\
\text { week average) } \\
\text { within the first } \\
14 \text { days of RRT } \\
\text { initiation }\end{array}$ & No ESA & $\begin{array}{l}N=187 ; \\
\text { ESA(71); } \\
\text { control(116) }\end{array}$ & NA & $\begin{array}{l}\text { No difference in } \\
\text { transfusions. SCr at } \\
2 \text { weeks favored the ESA } \\
\text { arm but did not reach } \\
\text { statistical significance ( } p \\
=0.054 \text { ). No difference } \\
\text { in renal recovery or } \\
\text { renal survival }\end{array}$ \\
\hline $\begin{array}{l}\text { Tasanarong } \\
2013[28]\end{array}$ & $\begin{array}{l}\text { Thailand } \\
\text { (Thammasat } \\
\text { Chalerm Prakiat } \\
\text { Hospital) }\end{array}$ & $\begin{array}{l}\text { Patients scheduled } \\
\text { for elective CABG } \\
\text { using CPB }\end{array}$ & $\begin{array}{l}\text { epoetin } \beta \text { ( } 200 \\
\text { U/kg; Recormon) } 3 \\
\mathrm{~d} \text { before CABG and } \\
100 \mathrm{U} / \mathrm{kg} \text { at the } \\
\text { operation time. }\end{array}$ & $\begin{array}{l}\text { Same } \\
\text { volume \& } \\
\text { schedule } \\
\text { of 0.9\% } \\
\text { saline }\end{array}$ & $\begin{array}{l}N=100: \\
\text { ESA(50), } \\
\text { control(50) }\end{array}$ & $\begin{array}{l}\geq 0.3 \mathrm{mg} / \mathrm{dl} \text { or } \geq 50 \% \\
\text { increase in sCr from } \\
\text { baseline within the } \\
\text { first } 48 \text { h post- } \\
\text { operation according } \\
\text { to the KDIGO } 2012 \\
\text { criteria. }\end{array}$ & $\begin{array}{l}\text { No difference in } \mathrm{Hb} \text {. sCr } \\
\text { increase and eGFR } \\
\text { decrease was lower in } \\
\text { the ESA group. Mean } \\
\text { urine NGAL group was } \\
\text { lower in the ESA group } \\
2 \mathrm{~h} \& 18 \mathrm{~h} \text {. }\end{array}$ \\
\hline $\begin{array}{l}\text { Yoo } 2011 \\
{[29]}\end{array}$ & $\begin{array}{l}\text { Korea (Yonsei } \\
\text { University } \\
\text { Health System, } \\
\text { Seoul) }\end{array}$ & $\begin{array}{l}\text { Patients scheduled } \\
\text { for valvular heart } \\
\text { surgery (VHS) with } \\
\text { preoperative } \\
\text { anemia }\end{array}$ & $\begin{array}{l}\text { Epoetin a (500 } \\
\text { IU/kg (iv); Epocain } \\
\text { and } 200 \text { mg iron } \\
\text { sucrose (iv)) 16- } \\
24 \text { h pre-surgery }\end{array}$ & $\begin{array}{l}\text { Equivalent } \\
\text { volume of } \\
\text { normal } \\
\text { saline }\end{array}$ & $\begin{array}{l}N=74: \\
\operatorname{ESA}(37) \\
\text { control(37) }\end{array}$ & $\begin{array}{l}\text { Increased sCr of } \\
0.3 \mathrm{mg} / \mathrm{dl} \text {, or } 50- \\
200 \% \text { from baseline, } \\
\text { using modified RIFLE } \\
\text { classification within } \\
48 \mathrm{~h} \text { after surgery }\end{array}$ & $\begin{array}{l}\text { Reduced transfusions. } \\
\text { No difference in } \\
\text { mortality }\end{array}$ \\
\hline
\end{tabular}

using non-creatinine-based renal biomarkers did not demonstrated significant reno-protection by ESAs. In 3 trials urine or plasma NGAL or serum cystatin C) were the same in both groups; in the 4th, urinary NGAL was lower in the ESA arm, although the significance of this difference is uncertain. 


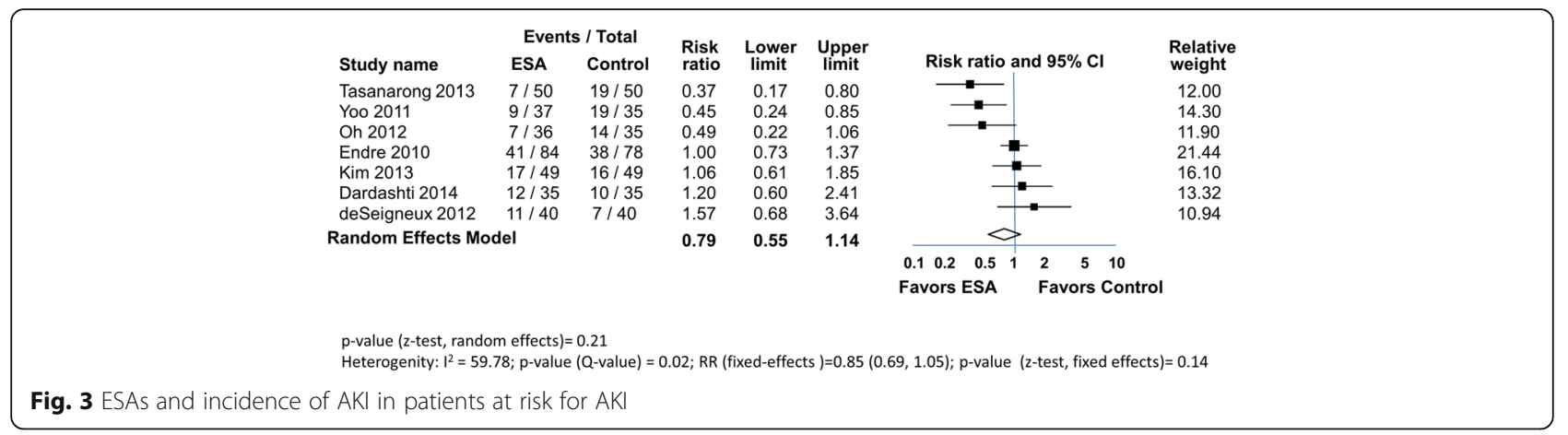

\section{Renal transplant trials}

Reinstitution of blood flow in cadaveric or live donor kidneys activates a sequence of events that results in renal injury, which may result in the development of DGF. DGF can translate into a decrease in long-term graft survival. In most ESA trials in transplant patients [14, 23, 30-36], DGF was defined as a requirement for dialysis within 7 days of the transplant [37]. In trials where multiple definitions were presented, data according to this definition was used. However, in some papers the definition of DGF was not disclosed, or an alternate measure was used (Table 3 ). The trial sizes were small to moderate in size (29-181 subjects). Like AKI trials, the number of ESA administrations were limited with little/no change in $\mathrm{Hb}$.

A meta-analysis with 450 subjects utilizing the DGF endpoint (7 trials), is shown in Fig. 4. DGF developed in 92 of $223(41 \%)$ in the ESA arms and 106 of 227 (47\%) in the control arms. The RR was neutral using random or fixed effects models $(0.96$ [0.83, 1.10]. Heterogeneity was low $\left(\mathrm{I}^{2}=0 \%\right)$.

Meta-analysis of long term graft loss over 1 year in four trials showed similar outcomes (Fig. 5). Fifteen of 221 subjects $(6.8 \%)$ had graft loss in the ESA arms and 21 of $241(8.7 \%)$ in the control arms. The RR $(0.78[0.41,1.48])$ slightly favored the ESA arm but did not reach statistical significance. Heterogeneity was low $\left(\mathrm{I}^{2}=0 \%\right)$. Excluding the retrospective study [23] reduced the apparent benefit with 9/139 (6.5\%) in the ESA arm and 10/142 (7.0\%) having graft loss, and the RR was closer to neutral, but with a larger range $(0.90[0.37,2.15])$.

In the 7 trials, additional renal outcomes were reported that showed no differences between ESA and no-ESA groups (Table 3). These included creatininebased endpoints (6 trials), eGFR (3 trials), proteinuria ( 1 trial), histological indices in graft biopsies at 6 weeks and 6 months post-transplant (1 trial), and low molecular weight urinary protein AKI biomarkers (NGAL and IL-18) (1 trial) [34].

\section{Anemia correction trials}

CKD patients are often anemic, and ESA treatment to increase and maintain $\mathrm{Hb}$ levels is long-term. Therefore, analysis of ESA anemia correction clinical trials is a potentially useful method to assess the effect of $\mathrm{Hb}$ increases, and oxygen delivery to renal tissues, on renal disease progression.

In the 19 anemia correction trials identified, CKD patients were typically divided into 2 groups; those remaining at their starting $\mathrm{Hb}$ (control) and those where ESAs were used to target a higher $\mathrm{Hb}$. ESAs in the 19 trials [18, 38-55] were typically given 1-3 times per week to raise and maintain target $\mathrm{Hb}$ levels (Table 4). The achieved $\mathrm{Hb}$ levels in most trials were $11-13.5 \mathrm{~g} / \mathrm{dL}$, with increases of $1-2.5 \mathrm{~g} / \mathrm{dL}$ above the starting level. Trial duration ranged from 2 to 48 months. Many subjects in the lower $\mathrm{Hb}$ groups received ESAs, but at lower doses. In some trials, there was no ESA treatment of patients in the control groups. We performed metaanalysis on all trials and a separate meta-analysis of trials where subjects in the control groups did not receive ESAs (Fig. 6).

Patients that progressed to RRT included those that began dialysis or received a transplant. In one trial a patient withdrew because of sepsis and AKI [48]. This event was included in the RRT endpoint of that study. No patients progressed to dialysis in either arm of the Lim 1989 [42] trial making it unsuitable for inclusion in a meta-analysis with a RRT endpoint.

The remaining 18 anemia correction trials had a combined total of 8020 subjects; 3964 in the treatment arm (higher $\mathrm{Hb}$ ) and 4056 in the comparator (low $\mathrm{Hb}$ control) arm. Trials were of varying size; 3 had over 600 subjects. The initial and achieved $\mathrm{Hbs}$ in the 2 groups are shown in Table 4.

Overall, 768 (19.4\%) of subjects in the treatment arm and $786(19.3 \%)$ in the control arm, progressed to RRT (Fig. 6). With meta-analysis, the RR (random effects) of progression to RRT was 1.04 [0.91, 1.18] with low heterogeneity $\left(\mathrm{I}^{2}=25.0 \%\right)$. This lack of effect on disease progression is supported in 18 trials by other 
Table 3 Kidney transplant studies

\begin{tabular}{|c|c|c|c|c|c|}
\hline Reference & Study Location & ESA & Control & $\begin{array}{l}\text { Subjects } \\
\text { (Total and } \\
\text { \# in groups) }\end{array}$ & DGF definition \\
\hline $\begin{array}{l}\text { Aydin } 2012 \\
\text { [31] }\end{array}$ & $\begin{array}{l}\text { Netherlands } \\
\text { (Leiden University } \\
\text { Medical Center) }\end{array}$ & $\begin{array}{l}\text { Epoetin } \beta(33,000 \mathrm{IU}) \text { on } 3 \\
\text { consecutive d, starting } 3- \\
4 \mathrm{~h} \text { before transplantation } \\
\& 24 \& 48 \text { h post- } \\
\text { reperfusion. }\end{array}$ & $\begin{array}{l}\text { Saline solution } \\
(0.9 \%)\end{array}$ & $\begin{array}{l}N=92: \\
\text { ESA(45), } \\
\text { control(47) }\end{array}$ & $\begin{array}{l}\text { Need for dialysis in the } \\
\text { first wk or if } \mathrm{sCr} \text { increase } \\
\text { remained unchanged or } \\
\text { decreased by less than } \\
10 \% \text { per } \mathrm{d} \text { during } 3 \\
\text { consecutive } \mathrm{d} \text { for more } \\
\text { than } 1 \text { week }\end{array}$ \\
\hline $\begin{array}{l}\text { Coupes } 2015 \\
\text { [30] }\end{array}$ & $\begin{array}{l}\text { United Kingdom } \\
\text { (Manchester } \\
\text { Royal Infirmary) }\end{array}$ & $\begin{array}{l}\text { Epoetin } \beta(100,000 \mathrm{U} \text {; } \\
33,000 \text { intraoperative and } \\
33,000 \text { at } 24 \text { and } 48 \text { h). }\end{array}$ & $\begin{array}{l}\text { Placebo (not } \\
\text { disclosed) }\end{array}$ & $\begin{array}{l}N=39: \\
\text { ESA(19), } \\
\text { control (20) }\end{array}$ & $\begin{array}{l}\text { Need for dialysis in first } \\
7 \text { days post-transplant }\end{array}$ \\
\hline
\end{tabular}

Other Outcomes

(Total and

$N=92: \quad$ Need for dialysis in the No significant differences

in $\mathrm{Hb}$, endogenous

creatinine clearance or

proteinuria

No difference in $\mathrm{Hb}$ or

number of transfusions.

No significant difference

in $\mathrm{s} C r$ or eGFR at any time

point to 90 day, No

difference in acute

rejection episodes, or

biomarkers (NGAL, KIM-1

or IL-18)

$\begin{array}{llll}\text { Hafer 2012 } & \begin{array}{l}\text { Germany } \\ \text { [32] }\end{array} & \text { Epoetin a (40,000 U (iv); } & \text { Placebo (not } \\ & \begin{array}{ll}\text { Medical School) } \\ \text { Merex) immediately before }\end{array} & \text { disclosed) } \\ & \text { reperfusion and d3 and d7 } & \text { same volume } \\ & \text { after transplantation } & \text { and } \\ & & \text { appearance }\end{array}$

Kamar 2010 France

$\begin{array}{ll}\text { [23] } & \text { (Department of } \\ & \text { Nephrology, } \\ & \text { Dialysis and } \\ & \text { Organ } \\ & \text { Transplantation, } \\ \text { CHU Rangueil, } \\ \text { Toulouse) }\end{array}$

Martinez, France (13

2010 [33] centers)

Epoetin a or epoetin $\beta$ (250 IU/kg/week) on d5 post-transplant, unless $\mathrm{Hb}$ level was above $12 \mathrm{~g} / \mathrm{dl}$ for women and $13 \mathrm{~g} / \mathrm{dl}$ for men. Cumulative ESA dose (D30) was $727 \pm 499 \mathrm{IU} / \mathrm{kg}$.

Epoetin $\beta$ (30.000 IU; Neorecormon) given before surgery and at $12 \mathrm{~h}, \mathrm{~d} 7$ and $\mathrm{d} 14$

$\begin{array}{ll}\text { Sureshkumar } & \text { Pennsylvania } \\ 2012[34] & \text { (USA) (Allegheny } \\ & \text { General Hospital, } \\ & \text { Pittsburgh, } \\ & \text { Pennsylvania) }\end{array}$

Van Biesen Belgium 2005 [35] (University Hospital Ghent)

$\begin{array}{ll}\text { Van Loo } & \text { Belgium } \\ 1996[36] & \text { (University } \\ & \text { Hospital, Gent, } \\ & \text { Belgium) }\end{array}$

Van Loo
Epoetin a (100,000 U (iv); Procrit) intraarterially immediately after reperfusion

Epoetin $\beta$ (100/IU/kg; Recormon) immediately after transplantation then thrice weekly to maintain $\mathrm{Hb}$ above $12 \mathrm{~g} / \mathrm{dL}$

Epoetin $\beta$ (within 1 week post transplant). Starting dose was $150 \mathrm{U} / \mathrm{kg} \mathrm{3X/}$ week (sc), for a maximum of 12 weeks to maintain Hct between 25\% and 35\%.
$N=88:$ ESA Urine output of less than (44), control $500 \mathrm{ml}$ in the first $24 \mathrm{~h}$ (44) appearance
Higher $\mathrm{Hb}$ at 2 and 4 but not 6 weeks. No significant difference in transfusions, eGFR 6 weeks or 12 months. No significant differences 6 weeks and 6 months post-transplant in histological indices.

Reduced $\mathrm{Hb}$ in ESA arm. No difference in transfusions. sCr levels were similar in both groups at 3, 6 and 12 months posttransplantation

No ESA during $\quad N=104$ : The need for dialysis the first month ESA (51), during the first wk after post control (53) transplantation transplantation

Matched placebo (not disclosed)
$N=72$ : ESA The need for dialysis (36), control within the first wk of (36) transplantation

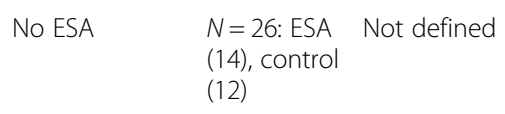

No ESA

$N=29$, ESA
$(14)$, control (15)

Higher $\mathrm{Hb}$ in ESA arm at 1 month. No difference in transfusions. No difference in $\mathrm{s} C r$ at any time point. No difference in eGFR at 1 or 3 months

No difference in $\mathrm{Hb}$, $\mathrm{s} C \mathrm{r}$, eGFR or urinary biomarkers of AKI (NGAL or IL-18)

Shorter time to target $\mathrm{Hb}$ in ESA arm. No difference in transfusions or $\mathrm{sCr}$ at 3 months

Increased $\mathrm{Hb}$ and reduced transfusions in ESA arm. No difference in $\mathrm{SCr}$ at any time point.

assessments of change in renal function, including proteinuria, or creatinine based markers where there were no significant differences reported between groups (Table 4). However, in one trial time to a doubling in serum creatinine was significantly slower in the ESA group (Kuriyama 1997) [41]. This anemia correction meta-analysis does not assess direct ESA effects per se because subjects in both arms may have received ESAs. 


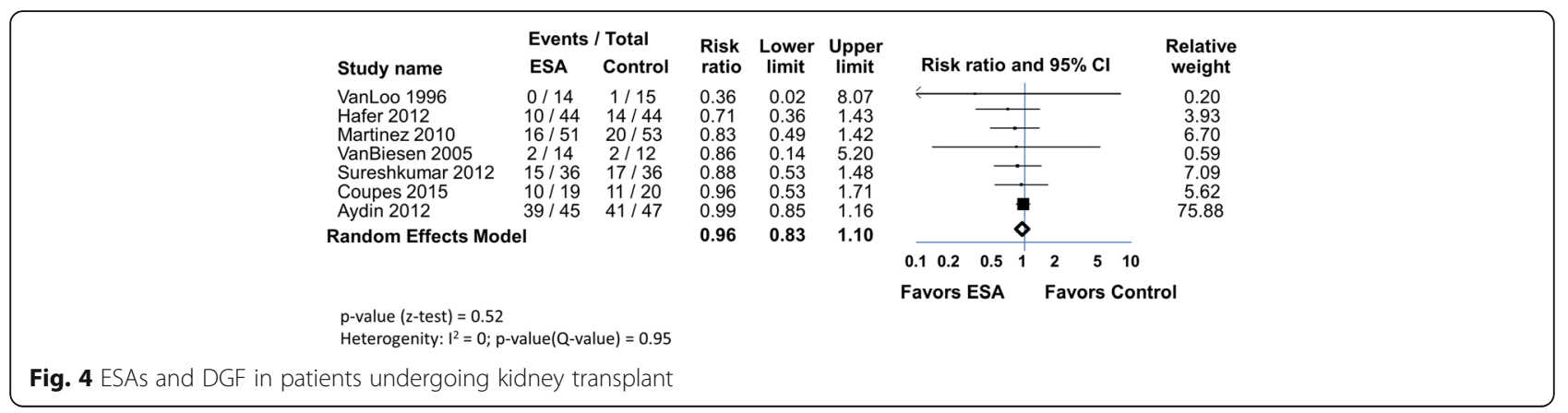

However, $\mathrm{Hb}$ levels increased in the ESA treatment/ high $\mathrm{Hb}$ arms. Thus the absence of benefit argues that anemia correction per se is not reno-protective.

In 6 of the 18 anemia correction trials, subjects in the comparator arm did not receive ESAs [18, 19, 38-43]. These trials included a total of 268 subjects. 42 of 129 in the ESA group (33\%) and 60 of 139 in the control group (43\%) progressed to dialysis. Meta-analysis showed a trend towards improvement in the progression to RRT in the ESA treatment group but this did not reach statistical significance; the RR according to the random effects model was 0.79 [0.6, 1.04] (Fig. 6). The result was similar using the mixed effects model. Heterogeneity was low. Measures of serum creatinine over time showed no statistical difference in 6 of the 7 trials. Thus this select analysis also does not support either direct or indirect (anemia correction) beneficial effect on renal disease progression by ESAs.

\section{Discussion}

We assessed potential beneficial effects of ESA treatment on acute or chronic renal disease. One potential benefit is that ESAs might increase renal tissue survival and therefore renal function following ischemic events due to an interaction of ESAs with receptors resident on the surface of renal cells resulting in an anti-apoptotic effect. Alternatively, there may be mitigation of the negative effects of anemia, since anemia is associated with an increased risk of renal disease progression and allograft loss over the long term [56, 57]. However, these meta-analyses showed no clear benefit of short-term ESAs in AKI and transplant trials, where there was little change in $\mathrm{Hb}$ levels, arguing an absence of direct benefit. There was also no significant ESA benefit in longerterm anemia correction trials, regardless of whether the comparator group received or did not receive ESAs. Thus there appeared to be little short or long-term reno-protective benefit of ESAs, via direct (via activation of EPOR or via an interaction of ESA with an EPOR:CD131 hybrid receptor [9]) or indirect (increased $\mathrm{Hb})$ mechanisms.

The lack of clear benefit of ESAs on renal disease is consistent with earlier meta-analyses. A meta-analysis with patients at risk for AKI showed no benefit of ESAs on incidence of AKI [58]. Another meta-analyses of effects of ESAs on CKD patients also showed no clear benefit on progression to RRT, comparing ESA treatment to no treatment [59] or comparing high vs low $\mathrm{Hb}$ targets [60, 61], nor was there was an association between ESA dose and annual GFR change or progression to ESRD [62].

Overall and to date, the potential cyto-protective effects of ESAs reported in animal models have generally not translated into benefit in humans, according to other studies examining benefit with other ischemic tissues [63]. There was no significant benefit of ESAs on infarct size in a meta-analyses of patients with acute STsegment elevation myocardial infarction [64, 65], and no effect on nonfatal heart related events in a meta-analysis of ESA-treated patients with heart failure [66]. There was also no difference in a meta-analysis of retinopathy of prematurity in infants treated with ESAs [67]. There was no benefit of either ESA or increased $\mathrm{Hb}$ in an ESA trial on patients with traumatic brain injury $[68,69]$, and

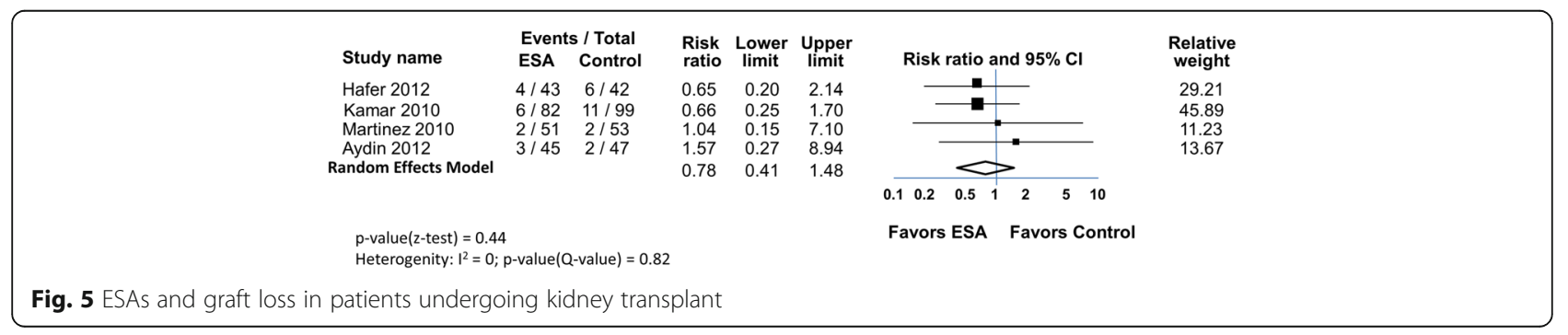


Table 4 Anemia correction studies

\begin{tabular}{|c|c|c|c|c|c|c|c|}
\hline Reference & Study Location & ESA & $\begin{array}{l}\text { Duration of } \\
\text { Therapy }\end{array}$ & Comparator Arm & $\begin{array}{l}\text { Subjects } \\
\text { (Total } \\
\text { and \# in } \\
\text { groups) }\end{array}$ & $\begin{array}{l}\text { Starting vs } \\
\text { Achieved } \\
\text { Hb High }(\mathrm{H}) \\
\text { or low }(\mathrm{L}) \mathrm{Hb} \\
\text { Group }(\mathrm{g} / \mathrm{dL})\end{array}$ & Other Renal Outcomes \\
\hline $\begin{array}{l}\text { Abraham } \\
1990[38]\end{array}$ & $\begin{array}{l}\text { Hennepin } \\
\text { County } \\
\text { Medical Center } \\
\text { Minneapolis } \\
\text { Minn (USA) }\end{array}$ & $\begin{array}{l}\text { Epoetin a }(50- \\
150 \mathrm{U} / \mathrm{Kg} 3 \mathrm{X} / \mathrm{w}) \\
\text { to raise Hct to } \\
37 \% \text { vs } 29 \%\end{array}$ & $\begin{array}{l}8-12 \text { weeks to } \\
\text { raise } \mathrm{Hct} \text { then } \\
\text { patients } \\
\text { received ESA }\end{array}$ & Placebo (unspecified) & $\begin{array}{l}N=8: \\
\text { ESA(4), } \\
\text { control(4) }\end{array}$ & $\begin{array}{l}\text { L: } 9.3 \text { vs } 9.7 \\
\text { H: } 10.7 \text { vs } \\
12.3\end{array}$ & $\begin{array}{l}\text { After } 18 \text { weeks there was } \\
\text { no difference in the } 1 / \mathrm{s} C r \\
\text { curves and no difference in } \\
\text { protein excretion }\end{array}$ \\
\hline $\begin{array}{l}\text { Clyne } 1992 \\
\text { [39] }\end{array}$ & $\begin{array}{l}\text { Karolinska } \\
\text { Hospital, } \\
\text { Danderyd } \\
\text { Hospital } \\
\text { Stockholm } \\
\text { (Sweden) }\end{array}$ & $\begin{array}{l}\text { Epoetin } \beta \text { (300 } \\
\mathrm{U} / \mathrm{kg}) 1 \mathrm{X} / \text { week to } \\
\text { raise } \mathrm{Hb} \text { from } 8.6 \\
\text { to } 11.7 \mathrm{~g} / \mathrm{dL}\end{array}$ & 12 weeks & Placebo (unspecified) & $\begin{array}{l}N=22: \\
\text { ESA(12), } \\
\text { control(10) }\end{array}$ & $\begin{array}{l}\text { L: } 9.3 \text { vs } 9.4 \\
\text { H: } 8.7 \text { vs } 11.3\end{array}$ & $\begin{array}{l}\text { No change in eGFR in } \\
\text { either group. No significant } \\
\text { difference in change in } \mathrm{sCr}\end{array}$ \\
\hline $\begin{array}{l}\text { Kleinman } \\
1989[40]\end{array}$ & $\begin{array}{l}\text { Valley } \\
\text { Presbyterian } \\
\text { hospital, Van } \\
\text { Nuys California } \\
\text { (USA) }\end{array}$ & $\begin{array}{l}\text { ESA }(100 \mathrm{U} / \mathrm{kg} \\
3 \times / \text { week) to raise } \\
\text { hct from } 28 \text { to } \\
38-40 \%\end{array}$ & 12 weeks & Placebo (unspecified) & $\begin{array}{l}N=14: \\
\operatorname{ESA}(7), \\
\text { control(7) }\end{array}$ & $\begin{array}{l}\text { L: } 9.4 \text { vs } 9.4 \\
H: 9.4 \text { vs } 11.9\end{array}$ & $\begin{array}{l}\text { No difference in } \mathrm{s} C r \text { or } \\
\text { change in } \mathrm{s} C r\end{array}$ \\
\hline $\begin{array}{l}\text { Kuriyama } \\
1997[41]\end{array}$ & $\begin{array}{l}\text { Saiseikai } \\
\text { Central } \\
\text { hospital, Tokyo } \\
\text { Japan }\end{array}$ & $\begin{array}{l}\text { Epoetin } \beta \text { (6000 } \\
\text { U/week) to raise } \\
\text { hct from } 25.5 \text { to } \\
35.5 \%\end{array}$ & 36 weeks & No ESA & $\begin{array}{l}N=108: \\
\text { ESA(42), } \\
\text { control(66) }\end{array}$ & $\begin{array}{l}\mathrm{L}: 9.3 \text { vs } 8.4 \\
\text { High } \mathrm{Hb} \\
\text { control } \\
12.0 \text { vs } 10.7 \\
\mathrm{H}: 9.0 \text { vs } 11.8\end{array}$ & $\begin{array}{l}\text { Time to a doubling in } \mathrm{sCr} \\
\text { significantly slower in the } \\
\text { ESA group. }\end{array}$ \\
\hline $\begin{array}{l}\operatorname{Lim} \\
{[42]}\end{array}$ & $\begin{array}{l}\text { University of } \\
\text { lowa Hospitals' } \\
\text { Renal Clinic, } \\
\text { lowa (USA) }\end{array}$ & $\begin{array}{l}\text { ESA }(50,100 \text {, or } \\
150 \mathrm{U} / \mathrm{kg} 3 \mathrm{X} / \\
\text { week) }\end{array}$ & 8 weeks & Placebo (unspecified) & $\begin{array}{l}N=13: \\
\operatorname{ESA}(11) \\
\text { control(2) }\end{array}$ & $\begin{array}{l}\text { L: } 9,0 \text { vs } 12.7 \\
H: 9.0 \text { vs } 8.0\end{array}$ & $\begin{array}{l}\text { No change in renal } \\
\text { function over } 2 \text { months in } \\
\text { ESA group }\end{array}$ \\
\hline $\begin{array}{l}\operatorname{Lim} \\
{[43]}\end{array}$ & $\begin{array}{l}\text { University of } \\
\text { lowa Hospitals' } \\
\text { Renal Clinic, } \\
\text { lowa (USA) }\end{array}$ & $\begin{array}{l}\text { Epoetin a } 3 X / \\
\text { week, later } \\
\text { switched to } 1 X / \\
\text { week to raise Hct } \\
\text { from } 28 \text { to } 36 \%\end{array}$ & $\begin{array}{l}11.8 \pm \\
6.8 \text { months } \\
\text { (range 2.8-23.8) }\end{array}$ & No ESA & $\begin{array}{l}N=20: \\
\operatorname{ESA}(10) \\
\text { control(10) }\end{array}$ & $\begin{array}{l}L: 11.0 \text { vs } 9.0 \\
H: 9.3 \text { vs } 12.0\end{array}$ & $\begin{array}{l}\text { The rate of change in } \mathrm{sCr} \\
\text { was similar over } 12 \text { months }\end{array}$ \\
\hline $\begin{array}{l}\text { Revicki } 1995 \\
{[18]}\end{array}$ & USA & $\begin{array}{l}\text { Epoetin a (50 U/ } \\
\mathrm{kg}, 3 \mathrm{X} / \text { week) } \\
\text { then titrated to } \\
\text { increase Hct from } \\
27 \text { to } 35 \% .\end{array}$ & 48 weeks & No ESA & $\begin{array}{l}N=83: \\
\text { ESA(43), } \\
\text { control(40) }\end{array}$ & $\begin{array}{l}\mathrm{L}: 8.9 \text { vs } 8.6 \\
\mathrm{H}: 8.9 \text { vs } 10.5\end{array}$ & $\begin{array}{l}\text { No difference in change in } \\
\text { eGFR after } 48 \text { weeks, no } \\
\text { difference in time to } \\
\text { dialysis }\end{array}$ \\
\hline $\begin{array}{l}\text { Akizawa } \\
2011[44]\end{array}$ & Japan & $\begin{array}{l}\text { Darbepoetin alfa } \\
\text { (30 ug } 1 \mathrm{X} / \text { week) } \\
\text { to target } \mathrm{Hb} 11- \\
13 \mathrm{~g} / \mathrm{dL} .\end{array}$ & 48 weeks & $\begin{array}{l}\text { rHuEpo ( } 4000 \mathrm{U} / \text { week) } \\
\text { to maintain } \mathrm{Hb} \text { at } 9- \\
11 \mathrm{~g} / \mathrm{dL} \text {. All received at } \\
\text { least one dose of ESA }\end{array}$ & $\begin{array}{l}N=321: \\
\text { High Hb } \\
(161), \text { Low } \\
\text { Hb (160) }\end{array}$ & $\begin{array}{l}\text { L: } 9.2 \text { vs } 10.1 \\
\text { H: } 9.2 \text { vs } 11.9\end{array}$ & $\begin{array}{l}\text { No difference in } 2 \text { years } \\
\text { decline in eGFR }\end{array}$ \\
\hline $\begin{array}{l}\text { Cianciaruso } \\
2008[45]\end{array}$ & Italy & $\begin{array}{l}\text { Epoetin a (2000 } \\
\cup 1 \times / \text { week) to } \\
\text { maintain Hb at } \\
12-14 \mathrm{~g} / \mathrm{dL}\end{array}$ & 12 months & $\begin{array}{l}\text { No ESA unless } \mathrm{Hb} \\
\text { dropped below } 9 \mathrm{~g} / \mathrm{dL} \text {. } \\
\text { 2/49 received ESA }\end{array}$ & $\begin{array}{l}N=95: \\
\text { High Hb } \\
(46), \text { Low } \\
\mathrm{Hb}(49)\end{array}$ & $\begin{array}{l}\text { L: } 11.7 \text { vs } \\
11.4 \\
\text { H: } 11.6 \text { vs } \\
12.4\end{array}$ & $\begin{array}{l}\text { No significant difference in } \\
\text { eGFR or } \mathrm{s} C \mathrm{r}\end{array}$ \\
\hline $\begin{array}{l}\text { Drueke } \\
2006[46]\end{array}$ & $\begin{array}{l}94 \text { centers } 22 \\
\text { countries }\end{array}$ & $\begin{array}{l}\text { Epoetin } \beta \text { to raise } \\
\mathrm{Hb} \text { to a target of } \\
13-15 \mathrm{~g} / \mathrm{dL} \text {. } \\
\text { Median was } 5000 \\
\text { U } 1 \mathrm{X} / \text { week }\end{array}$ & 48 months & $\begin{array}{l}\mathrm{Hb} \text { targeted to }>10.5 \\
\mathrm{~g} / \mathrm{dL} \text {. ESA only if } \mathrm{Hb} \\
\text { dropped below } 10.5 \\
\mathrm{~g} / \mathrm{dL} \text {. } 67 \% \text { received } \\
\text { ESA during the study. } \\
\text { Median } 2000 \mathrm{U} 1 \mathrm{X} / \text { week }\end{array}$ & $\begin{array}{l}N=603: \\
\text { High Hb } \\
(301), \text { Low } \\
\text { Hb (302) }\end{array}$ & $\begin{array}{l}\text { L: } 11.6 \text { vs } \\
11.4 \\
\text { H: } 11.6 \text { vs } \\
13.5\end{array}$ & $\begin{array}{l}\text { No significant difference in } \\
\text { the last eGFR value before } \\
\text { initiation of dialysis. Time } \\
\text { to initiation of dialysis was } \\
\text { shorter in the high Hb group } \\
\text { at } 18 \text { months }(P=0.03) \text {. }\end{array}$ \\
\hline $\begin{array}{l}\text { Gouva } 2004 \\
{[47]}\end{array}$ & Greece & $\begin{array}{l}\text { Epoetin a }(50 \mathrm{U} / \\
\mathrm{kg} 1 \mathrm{x} / \text { week) to } \\
\text { raise } \mathrm{Hb} \text { from } 9- \\
11.6 \mathrm{~g} / \mathrm{dL} \text { to a } \mathrm{Hb} \\
\text { target of } 13 \mathrm{~g} / \mathrm{dL}\end{array}$ & $\begin{array}{l}\text { Treatment time } \\
\text { was a median } \\
\text { of } 22.5 \text { months } \\
\text { (range 16-24) }\end{array}$ & $\begin{array}{l}\text { No ESA for a median of } \\
12 \text { months (range } 7-19 \text { ), } \\
\text { then no ESA unless } \mathrm{Hb} \\
\text { dropped below } 9 \mathrm{~g} / \mathrm{dL} \text {. }\end{array}$ & $\begin{array}{l}N=88: \\
\text { High } \\
\text { Hb(45), } \\
\text { Low } \\
\text { Hb(43) }\end{array}$ & $\begin{array}{l}\text { L: } 10.1 \text { vs } \\
10.3 \\
\text { H: } 10.1 \text { vs } \\
12.9\end{array}$ & No difference in $\mathrm{sCr}$ \\
\hline $\begin{array}{l}\text { Levin } 2005 \\
{[48]}\end{array}$ & Canada & $\begin{array}{l}\text { Epoetin a (2000 U } \\
1 \mathrm{X} / \text { week) to raise } \\
\text { and maintain } \mathrm{Hb} \\
\text { at } 12.0-14.0 \mathrm{~g} / \mathrm{dL}\end{array}$ & 24 months & $\begin{array}{l}\text { Low } \mathrm{Hb}(<11 \mathrm{~g} / \mathrm{dL}), 16 / \\
74 \text { received ESA }\end{array}$ & $\begin{array}{l}N=172: \\
\text { High } \\
\mathrm{Hb}(85) \text { Low } \\
\mathrm{Hb}(87)\end{array}$ & $\begin{array}{l}\text { L: } 11.7 \text { vs } \\
11.4 \\
\text { H: } 11.8 \text { vs } \\
12.8\end{array}$ & $\begin{array}{l}\text { No difference in creatinine } \\
\text { clearance. Change in eGFR } \\
\text { slower in the treatment } \\
\text { group (not significant) }\end{array}$ \\
\hline
\end{tabular}


Table 4 Anemia correction studies (Continued)

\begin{tabular}{|c|c|c|c|c|c|c|c|}
\hline $\begin{array}{l}\text { MacDougall } \\
2007 \text { [49] }\end{array}$ & $\begin{array}{l}\text { United } \\
\text { Kingdom }\end{array}$ & $\begin{array}{l}\text { Epoetin a (1000 } \\
\cup 2 X / \text { week) to } \\
\text { maintain Hb at } \\
11.0 \mathrm{~g} / \mathrm{dl} \text {. Total } \\
\text { was } 190,000 \mathrm{U}\end{array}$ & 3 years & $\begin{array}{l}\text { No ESA until } \mathrm{Hb} \\
\text { dropped below } 9 \mathrm{~g} / \mathrm{dL} \\
\text { ( } 55 / 132 \text { received ESA; } \\
\text { total } 152,000 \mathrm{U}\end{array}$ & $\begin{array}{l}N=197: \\
\text { High } \\
\text { Hb(65), } \\
\text { Low } \\
\text { Hb(132) }\end{array}$ & $\begin{array}{l}\text { L: } 10.9 \text { vs } \\
10.5 \\
\text { H: } 10.8 \text { vs } \\
11.0\end{array}$ & $\begin{array}{l}\text { No difference in time to } \\
\text { dialysis, creatinine } \\
\text { clearance, change in } \\
\text { creatinine clearance or } \\
\text { death. }\end{array}$ \\
\hline $\begin{array}{l}\text { Pfeffer } 2009 \\
\text { [50] }\end{array}$ & $\begin{array}{l}623 \text { sites in } 24 \\
\text { countries }\end{array}$ & $\begin{array}{l}\text { Darbepoetin alfa } \\
0.75 \mathrm{mcg} / \mathrm{kg} \\
\text { (Q2W and } \\
\text { switched to QM); } \\
\text { to increase } \mathrm{Hb} \\
\text { from } 10.4 \text { to } \\
12.5 \mathrm{~g} / \mathrm{dL} \text {. }\end{array}$ & $\begin{array}{l}48 \text { months; } \\
\text { median } \\
\text { duration of } \\
29 \text { months }\end{array}$ & $\begin{array}{l}\text { No ESA until } \mathrm{Hb} \\
\text { dropped below } 9 \mathrm{~g} / \mathrm{dL} \text {, } \\
46 \% \text { received } 1 \text { or } \\
\text { more doses of ESA }\end{array}$ & $\begin{array}{l}N=4038 \\
\text { High } \\
\mathrm{Hb}(2012) \\
\text { low } \\
\mathrm{Hb}(2026)\end{array}$ & $\begin{array}{l}\text { L:10.4 vs } 10.6 \\
\text { H: } 10.5 \text { vs } \\
12.5\end{array}$ & $\begin{array}{l}\text { No difference in the renal } \\
\text { composite endpoint }\end{array}$ \\
\hline $\begin{array}{l}\text { Ritz } 2007 \\
{[51]}\end{array}$ & $\begin{array}{l}64 \text { centers in } \\
16 \text { countries }\end{array}$ & $\begin{array}{l}\text { Epoetin } \beta \text { ( } 2000 \\
\text { U/week) to a } \\
\text { target Hb of } 13- \\
15 \mathrm{~g} / \mathrm{dL} \text {. }\end{array}$ & 15 months & $\begin{array}{l}\text { Hb target of } 10.5- \\
11.5 \mathrm{~g} / \mathrm{dL} .13 / 82 \\
\text { patients received ESA }\end{array}$ & $\begin{array}{l}N=172: \\
\text { High } \\
\text { Hb(89), } \\
\text { Low } \\
\text { Hb(83) }\end{array}$ & $\begin{array}{l}\text { L: } 11.7 \text { vs } \\
12.1 \\
H: 11.9 \text { vs } \\
13.5\end{array}$ & $\begin{array}{l}\text { No effect on the rate of } \\
\text { decrease in creatinine } \\
\text { clearance, change in eGFR } \\
\text { or urine protein }\end{array}$ \\
\hline $\begin{array}{l}\text { Roger } 2004 \\
\text { [52] }\end{array}$ & $\begin{array}{l}\text { Australia and } \\
\text { New Zealand }\end{array}$ & $\begin{array}{l}\text { Epoetin a } 1 \mathrm{X} / \\
\text { week to increase } \\
\mathrm{Hb} \text { from } 10 \text { to } \\
13 \mathrm{~g} / \mathrm{dL}\end{array}$ & 24 months & $\begin{array}{l}\text { ESA if } \mathrm{Hb} \text { below } 9 \mathrm{~g} / \mathrm{dL} \text {, } \\
8 / 78 \text { received ESA }\end{array}$ & $\begin{array}{l}N=155: \\
\text { High } \\
\text { Hb(75), } \\
\text { Low } \\
\text { Hb(80) }\end{array}$ & $\begin{array}{l}\text { L: } 11.2 \text { vs } \\
11.0 \\
H: 11.2 \text { vs } \\
12.2\end{array}$ & $\begin{array}{l}\text { No difference eGFR or } \\
\text { creatinine clearance at } \\
2 \text { years }\end{array}$ \\
\hline $\begin{array}{l}\text { Rossert } \\
2006[53]\end{array}$ & $\begin{array}{l}93 \text { centers in } \\
22 \text { countries }\end{array}$ & $\begin{array}{l}\text { Epoetin a (25- } \\
100 \mathrm{U} / \mathrm{kg} 1 \mathrm{X} / \\
\text { week) to a Hb } \\
\text { target of } 13- \\
15 \mathrm{~g} / \mathrm{dL} \text {. Median } \\
\text { dose was } \\
4,514 \mathrm{IU} / \text { week }\end{array}$ & $\begin{array}{l}4 \text { months } \mathrm{Hb} \\
\text { stabilization } \\
\text { then } \\
7.4 \text { months } \\
\text { maintenance } \\
\text { (high } \mathrm{Hb} \text { ) or } \\
8.3 \text { months } \\
\text { (low } \mathrm{Hb} \text { ) }\end{array}$ & $\begin{array}{l}\text { Hb target of } 11-12 \mathrm{~g} / \\
\text { day. } 65 / 195 \text { received at } \\
\text { least } 1 \text { ESA dose. Ave } \\
\text { dose } 2,730 \text { IU/week } \\
\text { (333-7667) }\end{array}$ & $\begin{array}{l}N=390: \\
\text { High } \\
\text { Hb(195), } \\
\text { Low } \\
\text { Hb(195) }\end{array}$ & $\begin{array}{l}\text { L: } 11.5 \text { vs } \\
11.7 \\
\text { H: } 11.6 \text { vs } \\
13.9\end{array}$ & $\begin{array}{l}\text { No significant differences } \\
\text { in rates of decrease in } \\
\text { eGFR }\end{array}$ \\
\hline $\begin{array}{l}\text { Singh } 2006 \\
{[54]}\end{array}$ & $\begin{array}{l}130 \text { sites in } \\
\text { USA }\end{array}$ & $\begin{array}{l}\text { Epoetin a } 1 \mathrm{x} / \\
\text { week to achieve } \\
\mathrm{Hb} \text { target of } \\
13.5 \mathrm{~g} / \mathrm{dL} \text {. Ave } \\
11,215 \mathrm{U} / \text { week }\end{array}$ & $\begin{array}{l}\text { Median } \\
\text { duration } \\
16 \text { months; } 661 \\
\text { patients } \\
(46.2 \%) \\
\text { completed } \\
36 \text { months }\end{array}$ & $\begin{array}{l}\text { Target } \mathrm{Hb} \text { of } 11 \mathrm{~g} / \mathrm{dL} \\
\text { (709/717 received ESA) } \\
\text { Ave dose } 6276 \mathrm{U} / \text { week }\end{array}$ & $\begin{array}{l}N=1432: \\
\text { High Hb } \\
(715), \text { Low } \\
\mathrm{Hb}(717)\end{array}$ & $\begin{array}{l}\text { L: } 10.1 \text { vs } \\
11.3 \\
H: 10.1 \text { vs } \\
12.6\end{array}$ & $\begin{array}{l}\text { No difference in } \\
\text { hospitalization for RRT }\end{array}$ \\
\hline $\begin{array}{l}\text { Villar } 2011 \\
{[55]}\end{array}$ & $\begin{array}{l}15 \text { centers in } \\
\text { France }\end{array}$ & $\begin{array}{l}\text { ESA to target a } \\
\mathrm{Hb} \text { of } 13-14.9 \mathrm{~g} / \\
\mathrm{dL} \text {. Mean weekly } \\
\text { ESA dose } 6028 \pm \\
6729 \mathrm{IU}\end{array}$ & 24 months & $\begin{array}{l}\text { Target } \mathrm{Hb} \text { of } 11-12.9 \mathrm{~g} / \\
\mathrm{dL} \text {. Mean dose } 1558 \pm \\
1314 \text { UI/week }\end{array}$ & $\begin{array}{l}N=89: \\
\text { High Hb } \\
(46), \text { Low } \\
\text { Hb (43) }\end{array}$ & $\begin{array}{l}\text { L: } 11.5 \text { vs } \\
11.9 \\
H: 11.4 \text { vs } \\
13.2\end{array}$ & $\begin{array}{l}\text { No difference in proteinuria } \\
\text { or decline in eGFR ( } 2 \text { years) }\end{array}$ \\
\hline
\end{tabular}

there was no benefit in a phase 3 trial with ESA treatment of stroke patients [70]. Taken together, these observations suggest that ESAs may not have the broad, robust, non-hematopoietic protective abilities described by some investigators, at least not in humans.

The gap between preclinical reports of benefit of ESAs in animals, and the absence of similar robust benefit in humans, has several explanations. Dose and dose regimens may be different, or the animal studies used homogeneous animal types under controlled conditions that cannot be mimicked in the clinic. Another possibility is that a benefit may have been unobservable because of the trial designs used. In this AKI metaanalysis the subjects were primarily cardiac patients and did not have only ischemia to the kidney as in animal studies and therefore may be immune to potential reno-protective ESA benefits.
There could also be other induced mechanisms that may confound the outcome data. For example, sepsis can affect outcomes and blood pressure can increase with ESA treatment and can negatively correlate with renal outcomes [71, 72]. However, control of blood pressure did not affect progression to ESRD in a clinical trial [73].

Alternatively, the beneficial conclusions of preclinical animal studies need to be reconsidered. There are many reports in animals showing a lack of effect of ESAs [1, 74]. The reno-protective hypothesis assumes that EPOR is present, and functional, at significant level on the surface of renal cells. However reports of EPOR presence are either assumed according to responses in tissue culture and in animals, or based on western or immunohistochemistry studies with anti-EPOR antibodies now shown to be nonspecific [75]. Recently a specific antibody to EPOR was discovered and western blots 


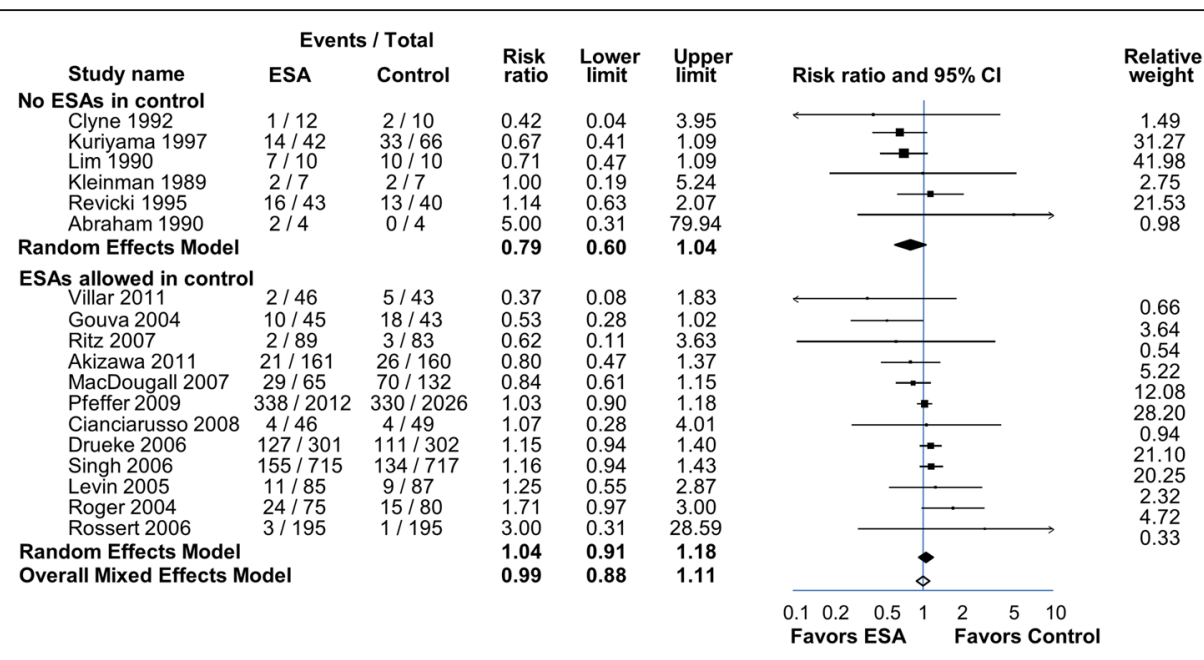

p-value (z-test, random effects progression $)=0.09 ; p$-value(z-test, random effects renal function $)=0.57 ; p$-value(z-test, mixed effects overall $)=0.84$

Heterogenity (progression): $1^{2}=0 ; \mathrm{p}$-value (Q-value) $=0.51$

Heterogenity (renal function): $I^{2}=25.01 ; p$-value $(Q$-value $)=0.20 ; R R($ fixed-effects $) 1.05(0.96,1.05) p$-value ( $z$-test, fixed effects) $=0.27$

Fig. 6 ESAs in anemic CKD patients. The 18 trials were divided into 2 groups. In 6 trials there was no ESAs administered in the control group. In 12 trials some patients in the control groups were given ESAs. The RR and range for each group (filled diamonds) and the overall RR (open diamond) are shown

on renal tissue showed few, if any, detectable EPOR raising further questions about the validity of the hypothesis [10].

These meta-analyses have limitations. Majorities of included trials were small, single center, and had modest event rates. The anemia correction trials were larger, but conclusions around direct effects were confounded by the frequent use of ESAs in the comparator arm, though trials where the comparator arm did not receive ESAs similarly showed no benefit. Within each grouping (CKD progression, AKI, transplantation) there were differences in patient selection, treatment regimen and outcome definition. Finally, the meta-analyses were based on aggregated, not individual patient level data, which precluded adjustments for confounding factors such as age and comorbidities.

\section{Conclusions}

In contrast to some preclinical studies demonstrating reno-protection by ESAs in animals, anemia correction, prophylaxis or post-injury intervention with ESAs provided no significant clinical reno-protection in humans. This suggests that ESAs may not have robust, nor reproducible direct, or indirect, benefits on renal function.

\section{Abbreviations}

AKI: Acute kidney injury; AKIN: Acute kidney injury network; CABG: Coronary artery bypass grafting; CKD: Chronic kidney disease; DGF: Delayed graft function; eGFR: Estimated glomerular filtration rate; EPO: Erythropoietin; EPOR: EPO receptor; ESA: Erythropoiesis stimulating agent; Hb: Hemoglobin; ITT: Intention to treat; RCT: Randomized controlled trial; RR: Risk ratios; RRT: Renal replacement therapy; SCr: Serum creatinine

\section{Acknowledgements}

We thank Allan Pollock for critically reviewing and providing comments of this manuscript

Availability of data and materials

All data generated or analyzed during this study are included in this published article.

\section{Authors' contributions}

SE conceived of the study, participated in the design, performed literature searches, data extraction, quality assessment, and drafting and revising the manuscript. DT participated in the design, performed statistical analysis, contributed to the interpretation of data and revision of the manuscript. ZE participated in the design, evaluation of the data, quality assessments, contributed to the interpretation of data and drafting and revision of the manuscript. All authors have reviewed and approved the final manuscript.

\section{Competing interests}

SE and DT are stockholders in Amgen Inc, a manufacturer and distributer of ESAs. SE was an employee, but currently receives no financial compensation from Amgen. Dianne Tomita is an employee of Amgen. None of the authors were directly compensated, had external funding sources or were provided administrative support for writing this paper. ZE has no financial conflicts to declare.

\section{Consent to publication}

Not applicable.

Ethical approval and consent to participate Not applicable.

\section{Author details}

${ }^{1}$ Amgen Inc, One Amgen Center, Newbury Park, Thousand Oaks, CA 91320, USA. ${ }^{2}$ Department of Nephrology, Prince of Wales Hospital and Clinical School, University of New South Wales, Sydney, NSW 2031, Australia.

Received: 6 February 2016 Accepted: 4 January 2017

Published online: 11 January 2017 


\section{References}

1. Elliott S, Sinclair AM. The effect of erythropoietin on normal and neoplastic cells. Biologics: Targets Therapy. 2012;6:163-89.

2. Lin FK, Suggs S, Lin CH, Browne JK, Smalling R, Egrie JC, et al. Cloning and expression of the human erythropoietin gene. Proc Natl Acad Sci U S A. 1985;82:7580-4

3. Sico JJ, Concato J, Wells CK, Lo AC, Nadeau SE, Williams LS, et al. Anemia is associated with poor outcomes in patients with less severe ischemic stroke. J Stroke Cerebrovasc Dis. 2013;22:271-8.

4. Kosiborod M, Smith GL, Radford MJ, Foody JM, Krumholz HM. The prognostic importance of anemia in patients with heart failure. Am J Med. 2003;114:112-9.

5. Abramson JL, Jurkovitz CT, Vaccarino V, Weintraub WS, McClellan W. Chronic kidney disease, anemia, and incident stroke in a middle-aged, communitybased population: the ARIC Study. Kidney Int. 2003;64:610-5.

6. Suzuki M, Hada Y, Akaishi M, Hiroe M, Aonuma K, Tsubakihara Y, et al. Effects of anemia correction by erythropoiesis-stimulating agents on cardiovascular function in non-dialysis patients with chronic kidney disease. Int Heart J. 2012;53:2012.

7. Bahlmann FH, Fliser D. Erythropoietin and renoprotection. Curr Opin Nephrol Hypertens. 2009;18:15-20.

8. Moore E, Bellomo R. Erythropoietin (EPO) in acute kidney injury. Ann Intensive Care. 2011;1:3.

9. Togel FE, Ahlstrom JD, Yang Y, Hu Z, Zhang P, Westenfelder C. Carbamylated Erythropoietin Outperforms Erythropoietin in the Treatment of AKI-on-CKD and Other AKI Models. J Am Soc Nephrol. 2016;27(11):3394-404.

10. Elliott S, Busse L, Swift S, McCaffery I, Rossi J, Kassner P, et al. Lack of expression and function of erythropoietin receptors in the kidney. Nephrol Dial Transplant. 2012;27:2733-45

11. Choukroun G, Kamar N, Dussol B, Etienne I, Cassuto-Viguier E, Toupance O, et al. Correction of postkidney transplant anemia reduces progression of allograft nephropathy. J Am Soc Nephrol. 2012;23:360-8.

12. Vasquez EM, Pollak R. Effect of pretransplant erythropoietin therapy on renal allograft outcome. Transplantation. 1996;62:1026-8.

13. Linde $T$, Ekberg $H$, Forslund $T$, Furuland $H$, Holdaas $H$, Nyberg $G$, et al. The use of pretransplant erythropoietin to normalize hemoglobin levels has no deleterious effects on renal transplantation outcome. Transplantation. 2001;71:79-82.

14. Lietz K, Lao M, Paczek L, Gorski A, Gaciong Z. The impact of pretransplant erythropoietin therapy on late outcomes of renal transplantation. Ann Transplant. 2003;8:17-24.

15. Fernandez-Lucas M, Marcen R, Villafruela J, Teruel JL, Tato A, Rivera M, et al. Effect of rHuEpo therapy in dialysis patients on endogenous erythropoietin synthesis after renal transplantation. Nephron. 1996;73:54-7.

16. Oh SW, Chin HJ, Chae DW, Na KY. Erythropoietin improves long-term outcomes in patients with acute kidney injury after coronary artery bypass grafting. J Korean Med Sci. 2012;27:506-11.

17. Song YR, Lee T, You SJ, Chin HJ, Chae DW, Lim C, et al. Prevention of acute kidney injury by erythropoietin in patients undergoing coronary artery bypass grafting: a pilot study. Am J Nephrol. 2009;30:253-60.

18. Revicki DA, Brown RE, Feeny DH, Henry D, Teehan BP, Rudnick MR, et al. Health-related quality of life associated with recombinant human erythropoietin therapy for predialysis chronic renal disease patients. Am J Kidney Dis. 1995;25:548-54.

19. Roth D, Smith RD, Schulman G, Steinman TI, Hatch FE, Rudnick MR, et al. Effects of recombinant human erythropoietin on renal function in chronic renal failure predialysis patients. Am J Kidney Dis. 1994;24:777-84.

20. Park J, Gage BF, Vijayan A. Use of EPO in critically ill patients with acute renal failure requiring renal replacement therapy. Am J Kidney Dis. 2005;46:791-8.

21. Olweny EO, Mir SA, Park SK, Tan YK, Faddegon S, Best SL, et al. Intra-operative erythropoietin during laparoscopic partial nephrectomy is not renoprotective. World J Urol. 2012;30:519-24.

22. Jadad AR, Moore RA, Carroll D, Jenkinson C, Reynolds DJ, Gavaghan DJ, et al. Assessing the quality of reports of randomized clinical trials: is blinding necessary? Control Clin Trials. 1996;17:1-12.

23. Kamar N, Reboux A-H, Cointault O, Esposito L, Cardeau-Desangles I, Lavayssiere $L$, et al. Impact of very early high doses of recombinant erythropoietin on anemia and allograft function in de novo kidneytransplant patients. Transpl Int. 2010;23:277-84.

24. Dardashti A, Ederoth P, Algotsson L, Bronden B, Grins E, Larsson M, et al. Erythropoietin and protection of renal function in cardiac surgery (the EPRICS Trial). Anesthesiology. 2014;121:582-90.
25. De SS, Ponte B, Weiss L, Pugin J, Romand JA, Martin P-Y, et al. Epoetin administrated after cardiac surgery: Effects on renal function and inflammation in a randomized controlled study. BMC Nephrol. 2012;13:132.

26. Endre ZH, Walker RJ, Pickering JW, Shaw GM, Frampton CM, Henderson SJ, et al. Early intervention with erythropoietin does not affect the outcome of acute kidney injury (the EARLYARF trial). Kidney Int. 2010;77:1020-30.

27. Kim J-H, Shim J-K, Song J-W, Song Y, Kim H-B, Kwak Y-L. Effect of erythropoietin on the incidence of acute kidney injury following complex valvular heart surgery: A double blind, randomized clinical trial of efficacy and safety. Crit Care. 2013;17:R254.

28. Tasanarong A, Duangchana S, Sumransurp S, Homvises B, Satdhabudha O. Prophylaxis with erythropoietin versus placebo reduces acute kidney injury and neutrophil gelatinase-associated lipocalin in patients undergoing cardiac surgery: A randomized, double-blind controlled trial. BMC Nephrol. 2013;14:136

29. Yoo Y-C, Shim J-K, Kim J-C, Jo Y-Y, Lee J-H, Kwak Y-L. Effect of single recombinant human erythropoietin injection on transfusion requirements in preoperatively anemic patients undergoing valvular heart surgery. Anesthesiology. 2011:115:929-37.

30. Coupes B, de Freitas DG, Roberts S, Read I, Riad H, Brenchley PE, et al. rhErythropoietin-b as a tissue protective agent in kidney transplantation: a pilot randomized controlled trial. BMC Res Notes. 2015;8:1.

31. Aydin Z, Mallat MJK, Schaapherder AFM, van Zonneveld AJ, Van KC, Rabelink TJ, et al. Randomized trial of short-course high-dose erythropoietin in donation after cardiac death kidney transplant recipients. Am J Transplant. 2012;12(7):1793-800.

32. Hafer C, Becker T, Kielstein JT, Bahlmann E, Schwarz A, Grinzoff N, et al. High-dose erythropoietin has no effect on short-or long-term graft function following deceased donor kidney transplantation. Kidney Int. 2012;81:314-20.

33. Martinez F, Kamar N, Pallet N, Lang P, Durrbach A, Lebranchu Y, et al. High dose epoetin beta in the first weeks following renal transplantation and delayed graft function: Results of the Neo-PDGF study: Brief communication. Am J Transplant. 2010;10:1704-9.

34. Sureshkumar KK, Hussain SM, Ko TY, Thai NL, Marcus RJ. Effect of high-dose erythropoietin on graft function after kidney transplantation: A randomized, double-blind clinical trial. Clin J Am Soc Nephrol. 2012;7:1498-506.

35. Van Biesen W, Vanholder R, Veys N, Verbeke F, Lameire N. Efficacy of erythropoietin administration in the treatment of anemia immediately after renal transplantation. Transplantation. 2005;79:367-8.

36. Van Loo A, Vanholder R, Bernaert P, Deroose J, Lameire N. Recombinant human erythropoietin corrects anaemia during the first weeks after renal transplantation - a randomized prospective study. Nephrol Dial Transplant. 1996:11:1815-21.

37. Siedlecki A, Irish W, Brennan DC. Delayed graft function in the kidney transplant. Am J Transplant. 2011;11:2279-96.

38. Abraham PA, Opsahl JA, Rachael KM, Asinger R, Halstenson CE. Renal function during erythropoietin therapy for anemia in predialysis chronic renal failure patients. Am J Nephrol. 1990;10:128-36.

39. Clyne $\mathrm{N}$, Jogestrand T. Effect of erythropoietin treatment on physical exercise capacity and on renal function in predialytic uremic patients. Nephron. 1992;60:390-6.

40. Kleinman KS, Schweitzer SU, Perdue ST, Bleifer KH, Abels RI. The use of recombinant human erythropoietin in the correction of anemia in predialysis patients and its effect on renal function: a double-blind, placebo-controlled trial. Am J Kidney Dis. 1989:14:486-95.

41. Kuriyama S, Tomonari H, Yoshida H, Hashimoto T, Kawaguchi Y, Sakai O. Reversal of anemia by erythropoietin therapy retards the progression of chronic renal failure, especially in nondiabetic patients. Nephron. 1997;77:176-85.

42. Lim VS, DeGowin RL, Zavala D, Kirchner PT, Abels R, Perry P, et al. Recombinant human erythropoietin treatment in pre-dialysis patients. A double-blind placebo-controlled trial. Ann Intern Med. 1989;110:108-14.

43. Lim VS, Fangman J, Flanigan MJ, DeGowin RL, Abels RT. Effect of recombinant human erythropoietin on renal function in humans. Kidney Int. 1990;37:131-6.

44. Akizawa T, Gejyo F, Nishi S, lino Y, Watanabe Y, Suzuki M, et al. Positive outcomes of high hemoglobin target in patients with chronic kidney disease not on dialysis: a randomized controlled study. Ther Apher Dial. 2011:15:431-40.

45. Cianciaruso B, Ravani P, Barrett BJ, Levin A, ITA EPO. Italian randomized trial of hemoglobin maintenance to prevent or delay left ventricular hypertrophy in chronic kidney disease. J Nephrol. 2008;21:861-70. 
46. Drueke TB, Locatelli F, Clyne N, Eckardt KU, Macdougall IC, Tsakiris D, et al. Normalization of hemoglobin level in patients with chronic kidney disease and anemia. N Engl J Med. 2006;355:2071-84.

47. Gouva C, Nikolopoulos P, loannidis JP, Siamopoulos KC. Treating anemia early in renal failure patients slows the decline of renal function: a randomized controlled trial. Kidney Int. 2004;66:753-60.

48. Levin A, Djurdjev O, Thompson C, Barrett B, Ethier J, Carlisle E, et al. Canadian randomized trial of hemoglobin maintenance to prevent or delay left ventricular mass growth in patients with CKD. Am J Kidney Dis. 2005;46:799-811.

49. Macdougall IC, Temple RM, Kwan JT. Is early treatment of anaemia with epoetin-alpha beneficial to pre-dialysis chronic kidney disease patients? Results of a multicentre, open-label, prospective, randomized, comparative group trial. Nephrol Dial Transplant. 2007;22:784-93.

50. Pfeffer MA, Burdmann EA, Chen CY, Cooper ME, de Zeeuw D, Eckardt KU, et al. A Trial of Darbepoetin Alfa in Type 2 Diabetes and Chronic Kidney Disease. N Engl J Med. 2009;361:2019-32.

51. Ritz E, Laville M, Bilous RW, O'Donoghue D, Scherhag A, Burger U, et al. Target level for hemoglobin correction in patients with diabetes and CKD: primary results of the Anemia Correction in Diabetes (ACORD) Study. [Erratum appears in Am J Kidney Dis. 2007 Apr;49(4):562]. Am J Kidney Dis. 2007:49:194-207.

52. Roger SD, McMahon LP, Clarkson A, Disney A, Harris D, Hawley C, et al. Effects of early and late intervention with epoetin alpha on left ventricular mass among patients with chronic kidney disease (stage 3 or 4): results of a randomized clinical trial. J Am Soc Nephrol. 2004;15:148-56.

53. Rossert J, Levin A, Roger SD, Horl WH, Fouqueray B, Gassmann-Mayer C, et al. Effect of early correction of anemia on the progression of CKD. Am J Kidney Dis. 2006:47:738-50.

54. Singh AK, Szczech L, Tang KL, Barnhart H, Sapp S, Wolfson M, et al. Correction of anemia with epoetin alfa in chronic kidney disease. N Engl J Med. 2006;355:2085-98.

55. Villar E, Lievre M, Kessler M, Lemaitre V, Alamartine E, Rodier M, et al. Anemia normalization in patients with type 2 diabetes and chronic kidney disease: results of the NEPHRODIAB2 randomized trial. J Diabetes Complications. 2011;25:237-43.

56. Chhabra D, Grafals M, Skaro Al, Parker M, Gallon L. Impact of anemia after renal transplantation on patient and graft survival and on rate of acute rejection. Clin J Am Soc Nephrol. 2008;3:1168-74.

57. Kamar N, Rostaing L. Negative impact of one-year anemia on long-term patient and graft survival in kidney transplant patients receiving calcineurin inhibitors and mycophenolate mofetil. Transplantation. 2008;85:1120-4.

58. Tie HT, Luo MZ, Lin D, Zhang M, Wan JY, Wu QC. Erythropoietin administration for prevention of cardiac surgery-associated acute kidney injury: a metaanalysis of randomized controlled trials. Eur J Cardiothorac Surg. 2015;48:32-9.

59. Cody J, Daly C, Campbell M, Donaldson C, Khan I, Rabindranath K, et al. Recombinant human erythropoietin for chronic renal failure anaemia in pre-dialysis patients. Cochrane Database Syst Rev. 2005;20(3):CD003266.

60. Palmer SC, Navaneethan SD, Craig JC, Johnson DW, Tonelli M, Garg AX, et al. Meta-analysis: erythropoiesis-stimulating agents in patients with chronic kidney disease. Ann Intern Med. 2010;153:23-33.

61. Covic A, Nistor I, Donciu M-D, Dumea R, Bolignano D, Goldsmith D. Erythropoiesis-stimulating agents (ESA) for preventing the progression of chronic kidney disease: A meta-analysis of 19 studies. Am J Nephrol. 2014;40:13.

62. Koulouridis I, Alfayez M, Trikalinos TA, Balk EM, Jaber BL. Dose of ErythropoiesisStimulating Agents and Adverse Outcomes in CKD: A Metaregression Analysis. Am J Kidney Dis. 2013;61:44-56.

63. Solling C. Organ-protective and immunomodulatory effects of erythropoietin an update on recent clinical trials. Basic Clin Pharmacol Toxicol. 2012;110:113-21.

64. Li J, Xu H, Gao Q, Wen Y. Effect of erythropoiesis-stimulating agents in acute ST-segment elevation myocardial infarction: a systematic review. Eur J Clin Pharmacol. 2012;68:469-77.

65. Wen Y, Xu J, Ma X, Gao Q. High-dose erythropoietin in acute ST-segment elevation myocardial infarction: A meta-analysis of randomized controlled trials. Am J Cardiovasc Drugs. 2013;13:435-42.

66. Desai A, Lewis E, Solomon S, McMurray JJV, Pfeffer M. Impact of erythropoiesisstimulating agents on morbidity and mortality in patients with heart failure: An updated, post-TREAT meta-analysis. Eur J Heart Fail. 2010;12:936-42.

67. Ohlsson A, Aher SM. Early erythropoietin for preventing red blood cell transfusion in preterm and/or low birth weight infants. Cochrane Database Syst Rev. 2014;4:CD004863.
68. Robertson CS, Hannay HJ, Yamal JM, Gopinath S, Goodman JC, Tilley BC, et al. Effect of erythropoietin and transfusion threshold on neurological recovery after traumatic brain injury: a randomized clinical trial. JAMA. 2014;312:36-47.

69. Nichol A, French C, Little L, Haddad S, Presneill J, Arabi Y, et al. Erythropoietin in traumatic brain injury (EPO-TBI): a double-blind randomised controlled trial. Lancet. 2015;386:2499-506.

70. Ehrenreich $\mathrm{H}$, Weissenborn $\mathrm{K}$, Prange $\mathrm{H}$, Schneider D, Weimar C, Wartenberg K, et al. Recombinant human erythropoietin in the treatment of acute ischemic stroke. Stroke. 2009;40:e647-56.

71. Uzu T, Kida Y, Yamauchi A, Kume S, Isshiki K, Araki S, et al. The effects of blood pressure control levels on the renoprotection of type 2 diabetic patients without overt proteinuria. J Am Soc Hypertens. 2012;6:124-31.

72. Imai E, Ito S, Haneda M, Harada A, Kobayashi F, Yamasaki T, et al. Effects of blood pressure on renal and cardiovascular outcomes in Asian patients with type 2 diabetes and overt nephropathy: a post hoc analysis (ORIENT-blood pressure). Nephrol Dial Transplant. 2016;31:447-54.

73. Ruggenenti P, Perna A, Loriga G, Ganeva M, Ene-lordache B, Turturro M, et al. Blood-pressure control for renoprotection in patients with non-diabetic chronic renal disease (REIN-2): multicentre, randomised controlled trial. Lancet. 2005;365:939-46.

74. Sinclair AM, Coxon A, McCaffery I, Kaufman S, Paweletz K, Liu L, et al. Functional erythropoietin receptor is undetectable in endothelial, cardiac, neuronal, and renal cells. Blood. 2010;115:4264-72.

75. Elliott S, Busse L, Bass MB, Lu H, Sarosi I, Sinclair AM, et al. Anti-Epo receptor antibodies do not predict Epo receptor expression. Blood. 2006;107:1892-5.

76. DeSeigneux S, Ponte B, Weiss L, Pugin J, Romand JA, Martin P-Y, et al. Epoetin administrated after cardiac surgery: Effects on renal function and inflammation in a randomized controlled study. BMC Nephrol. 2012;13:132.

\section{Submit your next manuscript to BioMed Central and we will help you at every step:}

- We accept pre-submission inquiries

- Our selector tool helps you to find the most relevant journal

- We provide round the clock customer support

- Convenient online submission

- Thorough peer review

- Inclusion in PubMed and all major indexing services

- Maximum visibility for your research

Submit your manuscript at www.biomedcentral.com/submit
) Biomed Central 